
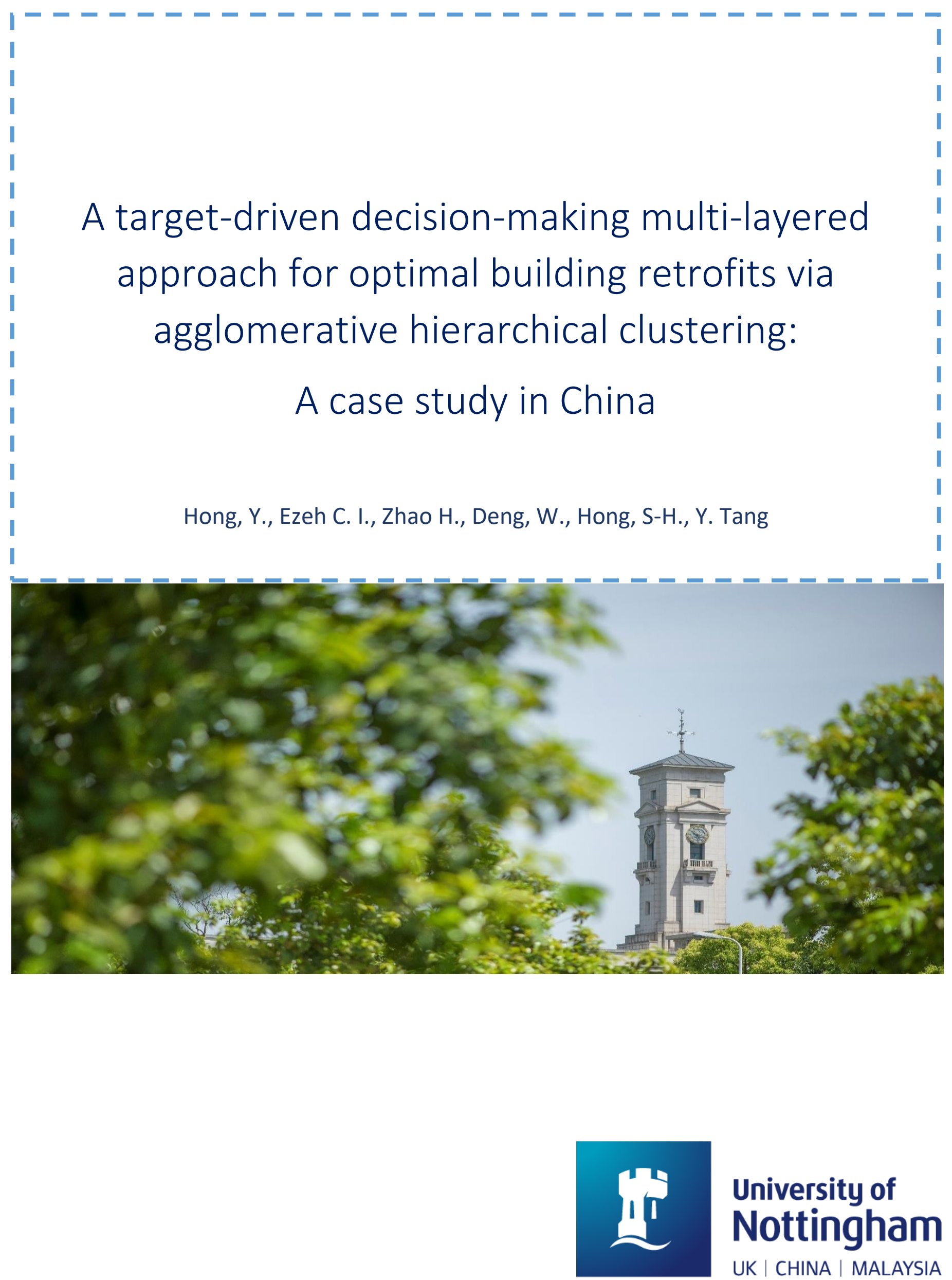

University of Nottingham 
University of Nottingham Ningbo China, 199 Taikang East Road, Ningbo, 315100, Zhejiang, China.

First published 2021

This work is made available under the terms of the Creative Commons Attribution 4.0 International License:

http://creativecommons.org/licenses/by/4.0

The work is licenced to the University of Nottingham Ningbo China under the Global University Publication Licence:

https://www.nottingham.edu.cn/en/library/documents/researchsupport/global-university-publications-licence-2.0.pdf 


\title{
A target-driven decision-making multi-layered approach for optima building retrofits via agglomerative hierarchical clustering: a case study in China
}

\author{
Hong, Y. ${ }^{1,2,3}$, Ezeh C. I. ${ }^{3}$, Zhao H. ${ }^{4}$, Deng, W. ${ }^{2, *}$, Hong, S-H. ${ }^{2}$, Y. Tang ${ }^{5}$ \\ $1=$ Laboratory for Manufacturing and Productivity \\ Massachusetts Institute of Technology \\ 77 Massachusetts Avenue, Cambridge, MA, USA \\ $2=$ Department of Architecture and Built Environment \\ University of Nottingham Ningbo \\ University Park, Ningbo, China \\ 3 = Shanghai Daren Construction Engineering Co. Ltd \\ Lianhang Road, Minhang District, Shanghai, China \\ $4=$ Shenzhen Institutes of Advanced Technology \\ Chinese Academy of Sciences \\ University Town of Shenzhen \\ $5=$ Department of Architecture and Built Environment \\ University of Nottingham UK \\ University Park, Nottingham, UK \\ * corresponding email = Wu.Deng@ $@$ nottingham.edu.cn
}

\begin{abstract}
The optimisation of energy, environmental and economic (3E) outcomes is the principal approach to identifying retrofit solutions for a sustainable built environment. By applying this approach and defining a set performance target, this study proposes a makeshift decision framework that integrates a data mining procedure (agglomerative hierarchical clustering (AHC)) into the multi-objective decision-making process to provide a simplified $3 \mathrm{E}$ assessment of building retrofits on a macro-scale. The framework comprises of three methodological models: (1) a building stock aggregation model, (2) an individualistic 3E model that provides the sensitivity analysis for (3) a life cycle cost-environmental assessment model. The framework is demonstrated and validated with a case study aimed at achieving the set EUI targets for low-rise office buildings (LOB) in Shanghai. The model defines 4 prototypical buildings for the existing LOB blocks, which are used for the individual evaluation of 12 commonly applied retrofit measures. Subsequently, a simplified LCC-environmental assessment was performed to evaluate the $3 \mathrm{E}$ prospects of 2048 possible retrofit combinations. The results uniquely identify retrofit solutions to attain set performance targets and optimal building performance. Furthermore, the decision criteria for different investment
\end{abstract}


scenarios are discussed. Overall, this study provides building investors an innovative framework for a facile and holistic assessment of a broader range of retrofit alternatives based on set performance targets.

Keyword: retrofit measures, cost analysis, life-cycle cost, AHC, low-rise office

\section{Introduction}

\subsection{Background}

Utilizing building retrofits has emerged as the primary concept for achieving a sustainably conscious society [1]. However, identifying the most suitable retrofits is hindered by many constraints associated with their implementation such as climatic condition, building typology, regulations and policies [2]. Typically, the application of numerous optimisation approaches (single-objective [3, 4] or multi-objective [5-7]) addresses this difficulty. Recent studies have demonstrated that a multi-objective optimisation approach is more suited to establish an optimal retrofit solution [8]. In this approach, the universal concept of optimising the energy, environmental and economic (3E) variables is emphasised to promote the interpretability, applicability and comparability between outcomes $[1,9,10]$. Social variables of building retrofits, such as the best possible compromise to enhance thermal comfort and indoor air quality, are also commonly considered $[8,11,12]$.

In most instances, the jointly considered decision variables in this field are electricity consumption, $\mathrm{CO}_{2}$ emission and cost indicators (investment, energy, life-cycle or payback period (PBP)). The optimization of these variables are defined by a set of objective functions, which commonly involve minimising the life-cycle costs (LCC) [6, 13]; maximising energy conservation (energy reduction impact), renewable sources adaptability and conservation compatibility $[6,7,14]$; and minimising $\mathrm{CO}_{2}$ and in some cases, other greenhouse gas (GHG) emissions [3, 5]. In summary, the objective function for an optimal retrofit should be an economical solution with minimal energy consumption and environmental impact. Nevertheless, most studies have only established this objective for designated typical buildings (micro-scale intervention) rather than for the entire building stock (meso- or macro-scale) [7, 14].

Generally, the implementation of energy efficiency policies concentrates on macroscale interventions. Hence, recent studies focus on establishing an evaluating model framework with an appropriate approach for retrofitting existing buildings on a macroscale [15]. In 2015, Lotteau and coworkers reported that the various adaptation of environmental assessment is the common approach for neighbourhood scale evaluation of the built environment in most reviewed studies [16]. Most recently, Mastrucci and coworkers pinpointed energy and environmental assessment models as the common 
framework for macro-scale evaluation [17]. However, to improve the interpretability of the results and comparability between outcomes, an economic indicator in addition to the potential energy and environmental impact indicators is recommended $[15,16]$. Broadly, it is uncommon to find studies of multi-objective retrofit optimisation on a macro scale with three or more objective functions owing to the complexities and uncertainties associated with the application of the approach on a broad scale.

Therefore, to bridge the abovementioned gaps, a macro-scale evaluating model that provides a holistic assessment is necessary. The model must enable a simplified optimization approach for $3 \mathrm{E}$ variables. Most importantly, the model will be meaningful to support decisions in sustainable urban planning and policymaking, particularly for developing societies. Accordingly, the model should proffer decisions based on investors' priority and set performance targets within that city/area.

\subsection{Novelty and contribution of this paper}

Given the present state of the art and considering the strengths and weaknesses of the outlined literature background, the novelty of this paper lies in the adoption of a comprehensive approach to providing a holistic (3E) evaluation of building retrofits on a macro-scale. While literature review emphasizes the complexities and lack of robust application of several decision-making models on a broader scale, this study highlights a model framework with a facile assessment methodology. The proposed approach incorporates a data mining analysis (agglomerative hierarchical clustering (AHC)) into a multi-objective decision-making process to aid building performance decisionmakers in selecting appropriate retrofit solutions under possible scenarios on a macroscale. There are five main advantages to this approach:

- Ab-initio prototyping of existing building stocks via AHC

- All 3E-assessed retrofit strategies are compared, not only to each other but also to the performance targets set by standards and regulations.

- Assessment of a broader range of retrofit measures under the energy demandside, energy supply-side and energy-conserving groups.

- Adopting AHC pair-wise comparison to establish the most appropriate retrofit solution.

- Establishing rational decision criteria based on the performance targets that can be adapted to stakeholders' priorities.

The paper is structured as follows. Section 2 describes the novel multi-objective decision-making model. In Section 3, the proposed model is demonstrated using a case 
study analysis. The design considerations, performance targets, outcomes and validation are described in this section to establish a novel user-oriented retrofit solution. Finally, some concluding remarks are made in Section 4.

\section{Model framework and methodology}

\subsection{Model framework with a novel approach of assessing building retrofits on a macro-scale}

The model framework is based on three methodological models: (1) a building stock aggregation model, (2) an individualistic 3E model that provides the sensitivity analysis for (3) a life cycle cost-environmental assessment model (which initiates the decisionmaking criteria) (see Fig. 1). In this study, the model framework assumes that an urban building model (with sufficient aggregated data of building stocks at building level) is not available in developing societies.

The building stock aggregation model is used to describe the existing buildings under investigation. It involves the characteristic-based evaluation of building energy performance to develop the relevant building prototypes, which will serve as the foundation for subsequent evaluations. Further explanation of this model is described in the literature [17]. However, the novelty of this study lies in the use of AHC technique to refine the generated non-dominated performance indexes during the building classification process to make it more intuitive and presentable.

The second model involves the individualistic 3E simulation of selected retrofit measures on the prototypical buildings. Simulation input variables are collected from literature, surrogate sources, questionnaire survey and on-site measurements. This model provides the sensitivity analysis based on selected decision variables required for subsequent analysis. In this study, the selected decision variables are electricity consumption, $\mathrm{CO}_{2}$ emission and cost indicators (investment costs (IC) and PBP).

The results from the individualistic $3 \mathrm{E}$ model are then used as the input data for the LCC-environmental assessment model, which is employed to evaluate the benefits of the combinatorial retrofit measures via a set of simplified numerical simulations. The LCC approach serves as a makeshift economic \& energy evaluating model as it depicts the trend between retrofit costs and energy-saving benefits. Here, the universal concept of minimizing the total LCC defines a set of optimal combinations of retrofit strategies $[8,12]$. By integrating the LCC approach with an environmental assessment model, a unique optimal strategy is obtained. It is highly recommended that LCA is employed as an environmental indicator to provide a comprehensive assessment. However, the $\mathrm{CO}_{2}$-savings potential is adopted in this study for simplicity. 
Also, this model framework simultaneously provides a range of suitable retrofit solutions for attaining the performance targets as stipulated by the set standards and regulations. Using an AHC data mining technique for pairwise comparison, the nondominated solutions can be further refined to identify the most probable solution for a macro-scale intervention [18]. Furthermore, by comparing the $3 \mathrm{E}$ benefits of the optimal retrofit solution to that for attaining the regulated performance targets, a set of decision indicators/criteria to guide investors in selecting the most reasonable solution is described. Overall, the proposed framework presents an innovative multi-objective decision-making model anchored on a clustering technique for a facile and holistic assessment of a broader range of retrofit measures. 


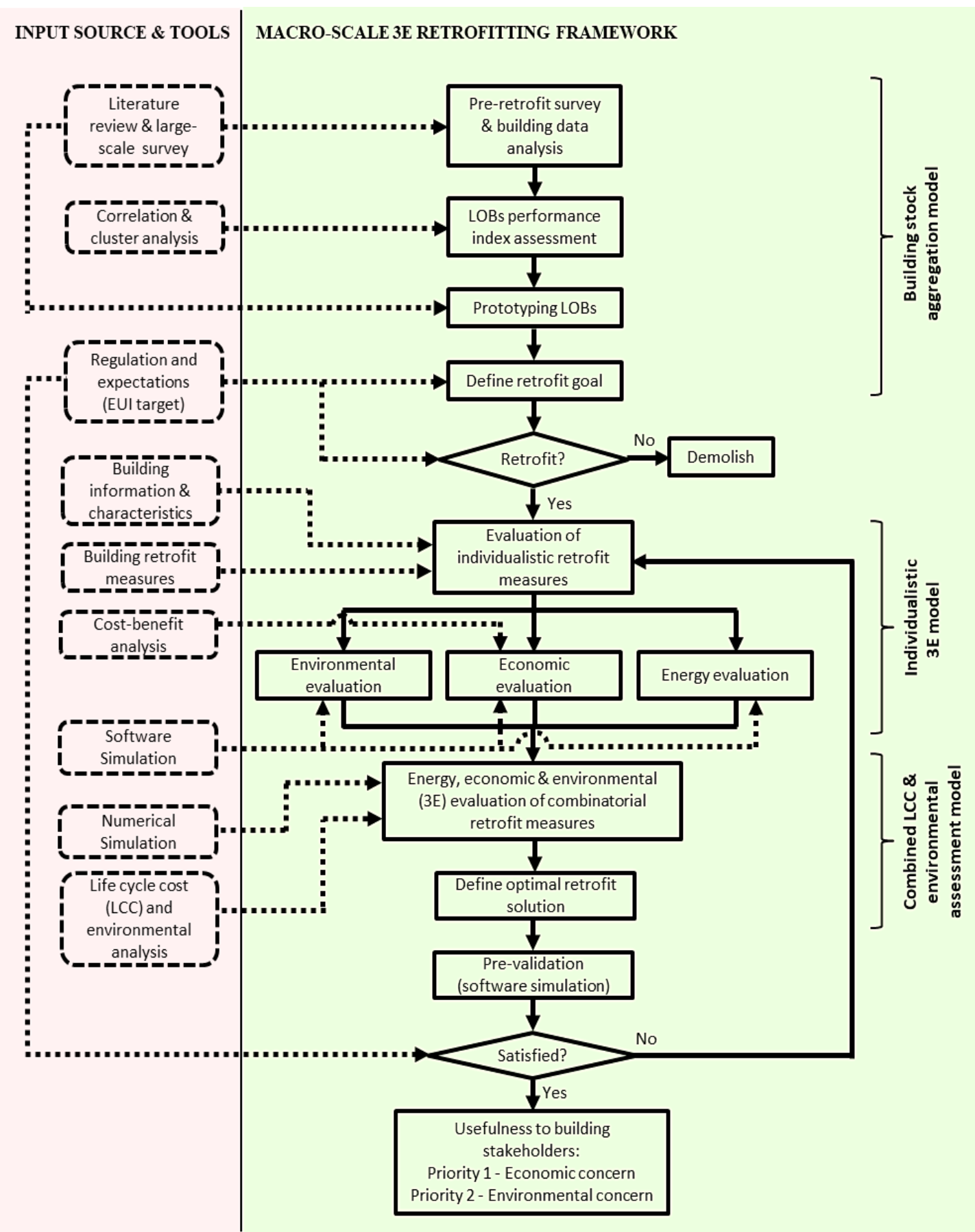

Fig. 1. Proposed macro-scale approach for retrofitting existing building blocks

\subsection{Research methodology}

\subsubsection{Building stock aggregation and prototyping}

The detailed description of this methodology is presented in our previous study [19]. Due to the lack of sufficient aggregated data, this methodology uses empirical databases generated from a large-scale survey of building samples and top-down macro-economic and statistic tools. Pearson and Biserial correlation analyses are adopted to define the performance index system (PIS) of the building energy efficiency. Given the large data size, further index refinement is conducted using cluster analysis. For simplicity and 
control of variables, the squared Euclidean distance and Z-score standardization methods are used as the similarity metric and for data normalization, respectively. By employing the clustering technique, a facile approach for identifying the key performance indexes (KPIs) is established, which are then used for building classification and prototyping. Each prototype represents a specific class of buildings that can be used to extrapolate the energy requirements of the entire stock.

\subsubsection{Assessment of the individualistic retrofit measures}

The assessment of the $3 \mathrm{E}$ impact of each retrofit measure on the prototypical buildings is conducted using a building performance modelling (Integrated Environmental Solutions Virtual Environment (IES-VE)) software. IES-VE has demonstrated a high level of accuracy and interoperability in estimating and predicting building performance [20]. For a more accurate simulation, measured weather data of the region was used. Thereafter, the simulation results for each prototype are compared with their original model to estimate their respective $3 \mathrm{E}$ impact.

\subsubsection{Assessment of the $3 E$ impact for all possible combinatorial retrofit strategies}

To precisely estimate the impact of all possible combinatorial retrofit strategies, it is crucial to consider that the measures in a particular retrofit strategy interact with each other. Hence, an appropriately integrated simulation of all the possible combinatorial retrofit measures is required. However, a simulation of this magnitude is impractical and requires a high computational cost. Therefore, a more numerical approach using the individually pre-simulated $3 \mathrm{E}$ results is recommended, but with a critical simplification to reduce calculation complexities. Details of the simplified numerical approach are presented in Section S1 (supporting document) and are based on related literature $[8,12]$.

The emphasis is on the LCC framework, which consists of nine steps. Readers are kindly referred to the literature for the LCC principles [21].

- Step 1: To calculate the IC for each combinatorial retrofit strategy as the sum of the IC of all included retrofit measures.

- Step 2: To calculate the annual energy cost (EC) for each strategy (which indicates the energy impact) using:

$$
E C=E_{T} \times E P
$$

where $E_{T}$ is the annual energy consumption (as computed in Section S1.1) and $E P$ is the price per unit electricity.

- Step 3: To calculate the total LCC for each strategy, as illustrated in Section S1.2.

- Step 4: To classify the retrofit development level (DL) using the IC values. Here, the IC values are sorted in ascending order and serve as the basis for rating the DL from $0-100 \%$. The strategy with no retrofit activity has a DL of $0 \%$, and the strategy with all retrofit activities has a DL of $100 \%$. 
- Step 5: To reduce the computational complexity due to the high number of data points by using the average of an 8-point bin of the DL, IC, EC, and total LCC as the new data points for the graph plotting.

- Step 6: To generate the IC, EC, and total LCC profiles based on the DL with a reasonable $\mathrm{R}^{2}$ correlation coefficient.

- Step 7: To determine the optimal retrofit solution at the minimum LCC with an environmental assessment model.

- Step 8: Using the generated profiles, a building performance threshold required to achieve the set performance targets is established. By calculating the required reduction in a selected variable to attain the set targets, a threshold IC value to achieve this variable change is estimated. All retrofit solutions with IC value beyond this threshold is considered suitable for attaining the set targets.

- Step 9: Finally, adopting the AHC data mining technique to determine the centroid strategy that represents all the possible retrofit solutions beyond the threshold value.

Finally, by comparing the 3E benefits from Step 7 and Step 9, a set of decision indicators/criteria to guide investors in selecting the most reasonable solution is described. These indicators/criteria are further discussed in Section 2.2.5.

\subsubsection{Clustering methodology}

\section{- Data preprocessing}

First, we normalize the aggregated/simulated data using the $\mathrm{z}$-score for effective comparison given the varying magnitude of data values. The z-score standardization method is employed for effective control of data variation and to prevent result skewness. This converts each data $\left(\mathrm{x}_{\mathrm{i}}\right)$ of a particular $i^{\text {th }}$ data group to have zero mean $\left(\mu_{\mathrm{i}}\right)$ and a standard deviation $\left(\sigma_{i}\right)$ of 1 . The $\mathrm{z}$-score $\left(Z_{x_{i}}\right)$ is computed as:

$$
Z_{x_{i}}=\frac{x_{i}-\mu_{i}}{\sigma_{i}}
$$

\section{- Cluster analysis}

To refine the generated non-dominant data towards the set objectives, an expanded twostep clustering method that combines an AHC with the $k$-means algorithm is employed. The first step involves the AHC algorithm. This is a bottom-up procedure where each data is initialized as a cluster and as the algorithm proceeds, clusters are further merged pairwise. Here, the goal is to minimize the squared Euclidean distance, $d$ between two datasets $(x$ and $y)$. For simplicity, the ward criterion is adopted for the minimisation.

$$
d=\sum_{i=1}^{I}\left(Z_{x_{i}}-Z_{y_{i}}\right)^{2}
$$

Besides, the algorithm defines the $k$ values of potential clusters and identifies possible outliers without any preconception by the user [22]. Also, it generates a dendrogram (tree-like diagram) presenting a visual interlink of the clusters. 
Following the identification of the number of clusters $\left(\boldsymbol{C}=\left\{C_{1}, C_{2}, \ldots, C_{k} \mid k \leq N\right\}\right)$ and the associated $k$ values for a set of $N$ data $\left(x_{1}, x_{2}, \ldots, x_{n}\right)$, the $k$-means algorithm for partitioning around a centroid is implemented as the second step. Here, the objective is to minimize the within-cluster variance so that:

$$
\underset{C}{\operatorname{argmin}} \sum_{i=1}^{k} \sum_{x \in C_{I}}\left\|x-\mu_{i}\right\|^{2}=\underset{C}{\operatorname{argmin}} \sum_{i=1}^{k}\left|C_{i}\right| \operatorname{Var} C_{i}
$$

where $\mu_{i}$ is the mean/centroid of data points in $C_{i}$.

In this algorithm, random centroids $\left(\mu_{1}{ }^{(1)}, \mu_{2}{ }^{(1)}, \ldots, \mu_{k}{ }^{(1)}\right)$ are initiated and each data point is assigned to the cluster with the nearest centroid via the least squared Euclidean distance:

$$
C_{i}^{(t)}=\left\{x_{a}:\left\|x_{a}-\mu_{i}^{(t)}\right\|^{2} \leq\left\|x_{a}-\mu_{j}^{(t)}\right\|^{2}\right\}
$$

where $x_{a}$ is the assigned data point to a cluster $C^{(t)}$.

Then, a new centroid is computed as the average of all data point within the cluster:

$$
\mu_{i}^{(t+1)}=\frac{1}{\left|C_{i}^{(t)}\right|} \sum_{x_{j} \in C_{i}^{(t)}} x_{j}
$$

This procedure is repeated until all data points are assigned to a cluster and the cluster assignment converges. All data points belonging to one centroid form a cluster.

\subsubsection{Decision indicators/criteria based on the investor type}

Following the identification of suitable combinatorial retrofit solutions required to attain the set performance targets and optimal building performance (at minimum LCC), it is appropriate to decide which of the solutions should be implemented for each building prototype. Generally, the optimal solution is recommended; however, the outcome of the retrofit strategy for the set target may be more favourable when matched with the optimal. The decision on which to be implemented between the two solutions varies with the stakeholder's priority. Using the IC and DL outcomes, two different scenarios are considered to assess the effect of the investor type on deciding a reasonable retrofit solution.

Scenario 1: When the retrofit cost (IC) is the primary concern of the investors. This scenario is very common in developing societies with such investors including owneroccupant, absent-owner and leasers [8]. In such scenario, matching the IC of the retrofit solutions for both the set target and minimum LCC (\%ICST:LCC) and comparing it with their matched energy reduction outcome (\% $\left.\mathrm{ER}_{\mathrm{ST} \text { :LCC }}\right)$ offers a facile decision criterion. Here, the more suitable decision will be to invest in the solution for the set target if Equation 7 applies; otherwise, the LCC solution is recommended.

$$
\% I C_{S T: L C C}<\% E R_{S T: L C C}
$$


where

$$
\begin{aligned}
\% I C_{S T: L C C} & =\frac{I C_{S T}}{I C_{\min L C C}} \times 100 \% \\
\% E R_{S T: L C C} & =\frac{E R_{S T}}{E R_{\min L C C}} \times 100 \%
\end{aligned}
$$

$I C_{j}$ and $E R_{j}$ are the investment cost and energy reduction impact at $j^{\text {th }}$ target (set performance target or minimum LCC).

Scenario 2: When the investor's priority is the retrofit development level (DL) required to attain a sustainable building. This is another prominent scenario in developing societies with the key investors considered as external stakeholders [8]. In this scenario, the investors are responsible for the environmental implication of each building. In this case, the deciding criterion for retrofit selection is suggested by comparing the matched DL of the retrofit solutions for attaining the set target and the minimum LCC (\%DLsT:LCC) with the respectively matched \%ERST:LCC. Here, the likely decision will be to invest in the solution for the set target if Equation 10 applies; otherwise, the LCC solution is more suitable.

$$
\% D L_{S T: L C C}<\% E R_{S T: L C C}
$$

where

$$
\% D L_{S T: L C C}=\frac{D L_{S T}}{D L_{\min L C C}} \times 100 \%
$$

$D L_{j}$ is the retrofit development level required to achieve the $j^{\text {th }}$ target (set performance target or minimum LCC). Here, the use of percentage changes reduces the error induced by the simplified approach, which ultimately leads to the formulation of innovative and customized deciding indicators/criteria.

\section{Case study analysis}

\subsection{Description of the selected city}

In this study, the city of Shanghai, which is one of the most industrial and populous city in the hot-summer-cold-winter (HSCW) climate zone of China [19] is selected. The city has a large share of old low-rise office buildings (LOB) (50\% of the commercial building blocks) [23, 24]. For demonstration, Minhang district is selected as the territorial boundary given that it has the largest non-residential buildings $\left(6,414 \mathrm{~m}^{2}\right.$ building area) with a vast age distribution [19]. To promote sustainable urban planning 
in this city, the old existing $\mathrm{LOB}$ requires retrofitting to meet the set energy performance target stipulated in China's regulation.

The set performance targets for commercial buildings are detailed in China's outcomebased energy-efficient standard, "Civil Building Energy Consumption Standard", which was developed in 2013 and became effective in 2016 [25]. In this standard, the performance target is presented as annual energy use intensity (EUI) target with a required and recommended value. These values vary with the building typology and its specific characteristics in different climate zones. Table 1 presents the required and recommended EUI targets for different categories of office buildings with 50 years of service life in the HSCW climate zone [25].

Category A defines buildings with operable windows and equipped with split HVAC systems, while category B consists of buildings without operable windows and are mainly served by mechanical ventilation and centralised HVAC systems. In this study, EUI targets under Category A was selected given that most LOB has operable windows with split HVAC systems. Moreover, given that most of the surveyed building blocks are opened to the public, the expected required and recommended EUI targets are 85 $\mathrm{kWh} / \mathrm{m}^{2}$ and $70 \mathrm{kWh} / \mathrm{m}^{2}$, respectively.

Table 1. The outcome-based standard for commercial buildings in the HSCW climate zone [25].

\begin{tabular}{lllrr}
\hline \multirow{2}{*}{$\begin{array}{l}\text { Building } \\
\text { Typology }\end{array}$} & Category & Classification & \multicolumn{2}{c}{$\begin{array}{c}\text { EUI in HSCW Climate zone } \\
\text { (Shanghai), } \mathbf{k W h} / \mathbf{m}^{2}\end{array}$} \\
\cline { 3 - 5 } & & & $\begin{array}{r}\text { Required } \\
\text { Recommended }\end{array}$ \\
\hline \multirow{3}{*}{ Office } & \multirow{2}{*}{ Cat. A } & Government & 70 & 50 \\
\cline { 3 - 5 } & \multirow{2}{*}{ Cat. B } & Commercial & 85 & 70 \\
\cline { 3 - 5 } & & Government & 90 & 65 \\
\hline
\end{tabular}

\subsection{Selected retrofit measures and design standards}

The retrofit measures selected for this study are founded on the region-based prescriptive measures from the design standards for commercial buildings in China [26], Chartered Institution of Building Services Engineers (CIBSE) [27], and other relevant literature [23, 24, 28, 29]. In total, twelve different retrofit measures are selected (see Table 2). The measures are classified into two classes: 1) energy-reducing (which includes demand-side and energy-conserving groups) and 2) energy-producing (primarily consisting of the supply-side group). For a detailed description of the various classification groups, readers are referred to the literature [28, 30]. For justification of the selected measures, kindly refer to our review study on commonly applied building 
retrofits in Shanghai and their expected design standards [24]. In summary, Table 2 also highlights the design standards for each measure.

Table 2. Details of specific retrofit measures

\begin{tabular}{|c|c|c|c|}
\hline Classes & Group & Activity & Design standards \\
\hline Orginal & - & - & $\begin{array}{l}\text { Models based on } 1980 \text { or } 2005 \\
\text { building codes in China [31] }\end{array}$ \\
\hline \multirow{10}{*}{$\begin{array}{l}\text { Energy- } \\
\text { reducing } \\
\text { measures }\end{array}$} & & $\begin{array}{l}\text { 1. Occupancy } \\
\text { Regimes } \\
\text { (Monitoring } \\
\text { Strategies) }\end{array}$ & $\begin{array}{l}\text { Adjusting the occupancy period } \\
\text { (operating time) from } 8: 00-18: 00 \text { to } \\
9: 00-17: 00 \text { and monitoring of } \\
\text { facilities [27] }\end{array}$ \\
\hline & $\begin{array}{l}\text { Energy } \\
\text { Conserving } \\
\text { Behaviours }\end{array}$ & $\begin{array}{l}\text { 2. Comfort } \\
\text { Requirements }\end{array}$ & $\begin{array}{l}\text { Reducing the internal temperature } \\
\text { requirement range by } 1{ }^{\circ} \mathrm{C}[27,32] \text {. } \\
\text { During summertime, the temperature } \\
\text { set range is changed to } 22-29^{\circ} \mathrm{C} \\
\text { from } 22-28^{\circ} \mathrm{C} \text {. During wintertime, } \\
\text { the range is set to } 15-24^{\circ} \mathrm{C} \text { from } 16 \text { - } \\
24^{\circ} \mathrm{C}[27] \text {. }\end{array}$ \\
\hline & \multirow{3}{*}{$\begin{array}{l}\text { Equipment/ } \\
\text { Lighting } \\
\text { System }\end{array}$} & $\begin{array}{l}\text { 3. Natural } \\
\text { Ventilation }\end{array}$ & $\begin{array}{l}\text { The infiltration rate was adjusted } \\
\text { from } 8.31 / \mathrm{s} \text { to } 81 / \mathrm{s} \text { according to } \\
\text { CIBSE and adequate monitoring of } \\
\text { the windows functions [27]. }\end{array}$ \\
\hline & & $\begin{array}{l}\text { 4. Replace } \\
\text { Lighting with } \\
\text { energy- } \\
\text { efficient ones }\end{array}$ & $\begin{array}{l}\text { Reducing the lighting power density } \\
\text { from } 15 \mathrm{~W} / \mathrm{m}^{2} \text { (before } 1980 \text { ) to } 9 \\
\mathrm{~W} / \mathrm{m}^{2} \text { (according to } 2014 \text { building } \\
\text { code, GB5018-2014) for buildings } \\
\text { before } 2005 \text {; and from } 11 \mathrm{~W} / \mathrm{m}^{2} \\
\text { ( } 2005 \text { building code } \mathrm{GB} 50189-2005 \text { ) } \\
\text { to } 9 \mathrm{~W} / \mathrm{m}^{2} \text { [26]. }\end{array}$ \\
\hline & & $\begin{array}{l}\text { 5. Energy- } \\
\text { efficient } \\
\text { HVAC }\end{array}$ & $\begin{array}{l}\text { Improve the energy-efficiency of } \\
\text { heating and cooling equipment to } 5.2 \\
\text { chiller COP, } 0.9 \mathrm{~kW} \text { heating SCoP, } \\
3.5 \mathrm{~kW} \text { cooling nominal EER and } 3.0 \\
\mathrm{~kW} \text { cooling seasonal EER [26]. }\end{array}$ \\
\hline & \multirow{5}{*}{$\begin{array}{l}\text { Building } \\
\text { Envelope }\end{array}$} & $\begin{array}{l}\text { 6. Insulate } \\
\text { ceilings }\end{array}$ & $\begin{array}{l}\text { add } 20 \mathrm{~mm} \text { XPS insulation material } \\
\text { on ceilings [33] }\end{array}$ \\
\hline & & $\begin{array}{l}\text { 7. Insulate } \\
\text { walls }\end{array}$ & $\begin{array}{l}\text { add } 160 \mathrm{~mm} \text { XPS insulation material } \\
\text { on walls [33] }\end{array}$ \\
\hline & & $\begin{array}{l}8 \text {. Insulate cool } \\
\text { roofs }\end{array}$ & $\begin{array}{l}\text { add } 150 \mathrm{~mm} \text { XPS insulation material } \\
\text { on cool roofs [33] }\end{array}$ \\
\hline & & $\begin{array}{l}\text { 9. Replace } \\
\text { Windows with } \\
\text { energy- } \\
\text { efficient ones }\end{array}$ & $\begin{array}{l}\text { Replacing windows with energy- } \\
\text { efficient ones }[34,35] \text { using 6low- } \\
\text { E+12air+6low-E+12air+6low-E } \\
\text { triple-glazed windows [33] }\end{array}$ \\
\hline & & $\begin{array}{l}\text { 10. Air- } \\
\text { tightness }\end{array}$ & $\begin{array}{l}\text { Changing the air-tightness } \\
\text { infiltration to } \mathrm{Na}=0.6 \text { ach according } \\
\text { to CIBSE [27]. }\end{array}$ \\
\hline
\end{tabular}




\begin{tabular}{llll}
\hline & & $\begin{array}{l}\text { 11. Install } \\
\text { solar PV } \\
\text { systems }\end{array}$ & $\begin{array}{l}\text { Installation of PV panel system with } \\
\text { a capacity of } 8.3 \mathrm{kWh} / \mathrm{m}^{2}[12,21] .\end{array}$ \\
\cline { 3 - 4 } $\begin{array}{l}\text { Energy- } \\
\text { producing } \\
\text { measures }\end{array}$ & $\begin{array}{l}\text { Renewable } \\
\text { energy } \\
\text { sources } \\
\text { (RES) }\end{array}$ & $\begin{array}{l}\text { 12. Install } \\
\text { geothermal } \\
\text { system }\end{array}$ & $\begin{array}{l}\text { Installation of a geothermal heat } \\
\text { pump for heating and cooling load. } \\
\text { Proposed energy reduction: } 50 \% \text { of } \\
\text { the building energy demand }[12,21] .\end{array}$ \\
\hline
\end{tabular}

\subsection{Results and discussions}

\subsubsection{LOB prototypes}

The prototyping approach employs a large-scale survey of existing LOB in Minhang district, Shanghai. Here, a survey of 10 randomly selected office parks with 136 LOB is conducted. The on-site and surrogate data collected are presented in our previous study [19]. Also, the study describes the proposed prototypical LOB used in this present study.

In summary, the construction year, window-wall (W/W) ratio and the number of floors are identified as the KPIs of LOB in Shanghai, which are then used to classify LOB into four prototypes based on the Chinese building codes and standards. Kindly see Section S2 (supporting document) for brief details of the LOB prototypes (hereby represented as LOP). The LOP are:

LOP1: LOB with W/W ratio between $0.2-0.4$ and 5 floors built before 2005 (C1); LOP2: LOB with W/W ratio < 0.2 and 3 floors built between $2006-2015$ (C2);

LOP3: LOB with W/W ratio > 0.4 and 4 floors; built between $2006-2015$ (C2);

LOP4: LOB with W/W ratio > 0.4 and 6 floors built between 2006 - 2015 (C2).

\subsubsection{Building performance based on the individualistic retrofit measures}

The building performance result for the individual retrofit measures on the four LOP is presented in Section S3 (supporting document). The result includes the energy (total electricity consumption), environmental $\left(\mathrm{CO}_{2}\right.$ emission) and economic (IC, annual electricity cost savings and PBP) implications. It is noteworthy that the environmental impact (reduction in $\mathrm{CO}_{2}$ emission) is commensurate to the energy impact (reduction in total electricity consumption). Besides, given that the RES capacity is fixed, its impact (in percentage) is parallel across all LOP.

The simulation result reveals that the adopted retrofit type is instrumental to the $3 \mathrm{E}$ outcome of the building. The total electricity consumption (in MWh) for the original (without retrofits) LOP1, LOP2, LOP3 and LOP4 are 1181.6, 164.03, 201.6 and 1266.8, respectively; with a corresponding EUI of $132.20 \mathrm{kWh} / \mathrm{m}^{2}, 98.52 \mathrm{kWh} / \mathrm{m}^{2}, 123.53$ $\mathrm{kWh} / \mathrm{m}^{2}$ and $116.71 \mathrm{kWh} / \mathrm{m}^{2}$, respectively. Expectedly, the variation in energy 
consumption is due to the distinct building areas. Nonetheless, a significant distinction is witnessed in the energy consumption of LOP2 and LOP3, despite having similar building areas. This variation can be attributed to the larger W/W ratio of LOP3, which has a higher likelihood of imparting a large energy implication depending on the building geometry $[34,35]$.

Regarding the energy (also environmental) impact, Fig. 2 shows a pictorial comparison of the impact of each retrofit measure on each LOP (as presented in the fourth column of the tabulated pre-simulation results in Section S3). Overall, all adopted measures significantly impacted the building's energy consumption, except for natural ventilation that showed approximately $1-3 \%$ reduction depending on the prototype. Specifically, prototypes within the $\mathrm{C} 2$ construction period (LOP2, LOP3 and LOP4) displayed an energy reduction $>2 \%$ after the natural ventilation was upgraded. In comparison to the ca. $1 \%$ reduction in LOP1, it is evident that the improved features of recent buildings, particularly the building envelope, enable significant energy reduction when passive retrofit strategies are incorporated in the building design. Other measures that displayed a greater energy impact in $\mathrm{C} 2$ than in $\mathrm{C} 1$ prototypes are the energy-conserving behaviours (changes in occupancy regimes and comfort requirements).

Concerning changes in occupancy regimes, ca. $10-13 \%$ energy reduction was witnessed in the $\mathrm{C} 2$ prototypes, whereas $c a$. $10 \%$ reduction was depicted in LOP1. Likewise, a greater energy reduction potential (about $7-10 \%$ ) was witnessed in the $\mathrm{C} 2$ prototypes in comparison to the $c a$. $5 \%$ reduction potential in LOP1 when changes in the comfort requirements were implemented. As earlier mentioned, these results confirm the beneficial role of building characteristics in supporting passive retrofit measures. For instance, the impact of an upgraded ventilation system is reinforced by the low infiltration rate in $\mathrm{C} 2$ prototypes. The same principle applies to the energyconserving behaviours, which when supported by the more efficient building systems and envelopes of $\mathrm{C} 2$ prototypes tends to promote a better energy performance than the $\mathrm{C} 1$ prototype. As a result, a higher energy impact is experienced in the $\mathrm{C} 2$ prototypes than in $\mathrm{C} 1$.

Regarding other measures (except for the RES), a greater energy reduction was witnessed in LOP1 than the LOP2, LOP3 and LOP4 prototypes. For example, considering the building envelop measures (upgrade in ceilings, walls, cooling roofs and windows), an average energy reduction of approximately $13.63 \%$ was witnessed in LOP1; however, an average reduction of approximately $8.59 \%, 5.62 \%$ and $7.36 \%$ was observed for the LOP2, LOP3 and LOP4 prototypes, respectively. This variation is expected and is related to the age of the building. The building facades and facilities of LOP1 are more outdated than that of the C2 prototypes, and as a result, are more energy inefficient. Consequently, an upgrade in these building features will offer a more significant impact on the LOP1 prototype. 


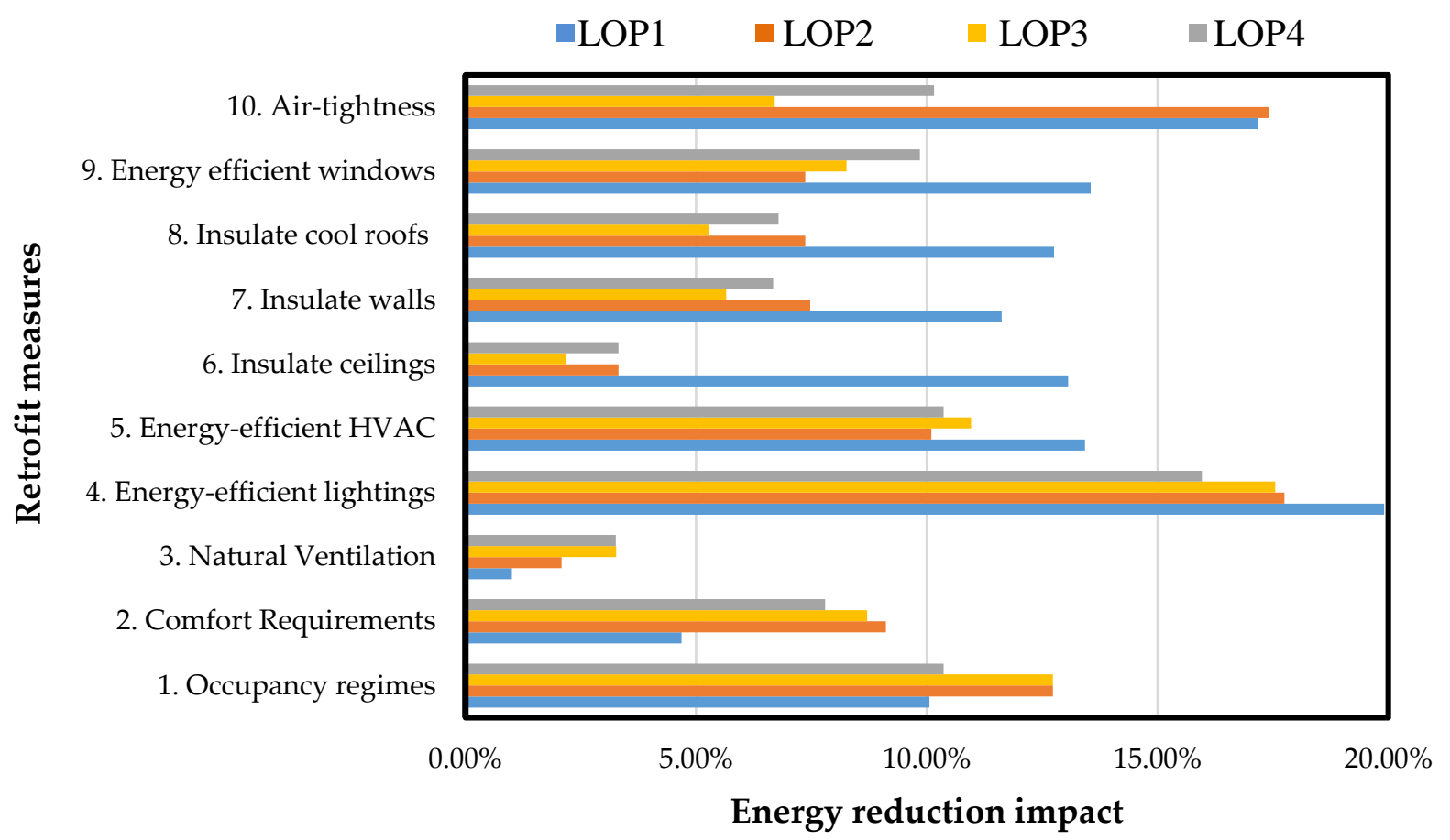

Fig. 2. Energy reduction impact of retrofit measures on each prototype.

Moreover, it is evident from Fig. 2 that the upgrade in lighting system and air-tightness are the most impactful measures across most LOP. Aside from these measures, altering the occupancy regime and upgrading the HVAC system also displayed good impact on energy reduction. Hence, the optimal retrofit solution should include these measures with high energy-saving (and $\mathrm{CO}_{2}$-saving) potential. However, this might not be the case from an economic perspective as some of these measures are relatively expensive and with low energy reduction impact per installation cost. Hence, further consideration of the optimal retrofit strategy should include cost indicators such as the IC and PBP.

About economic implication, three cost indicators (IC, annual savings and PBP) are assessed (Section S3). The IC is obtained with insights into China's retrofit price and is summarized for each retrofit measure in Fig. 3. Fig. 3 indicates that aside from the high installation cost of geothermal systems, upgrading the HVAC system is also cost demanding. The average IC (million RMB) for these measures across the four prototypes is 1.32 and 0.72 , respectively. Other relatively costly measures are the upgrade in building envelopes (walls and windows with an average of RMB 0.34 million and RMB 0.20 million, respectively) and lighting (average of RMB 0.17 million). Expectedly, the least expensive measures are the passive strategies, including an upgrade in natural ventilation (av. RMB 2,300) and changes in occupancy regimes (av. RMB 8,200). Moreover, the retrofit price was observed to be higher for LOP1 and LOP4 than for LOP2 and LOP3. This can be associated with the large building area of LOP1 and LOP4 $\left(8,937.5 \mathrm{~m}^{2}\right.$ and $10,854 \mathrm{~m}^{2}$, respectively) in comparison to that of LOP2 and LOP3 (1,665 $\mathrm{m}^{2}$ and $1,632 \mathrm{~m}^{2}$, respectively). 


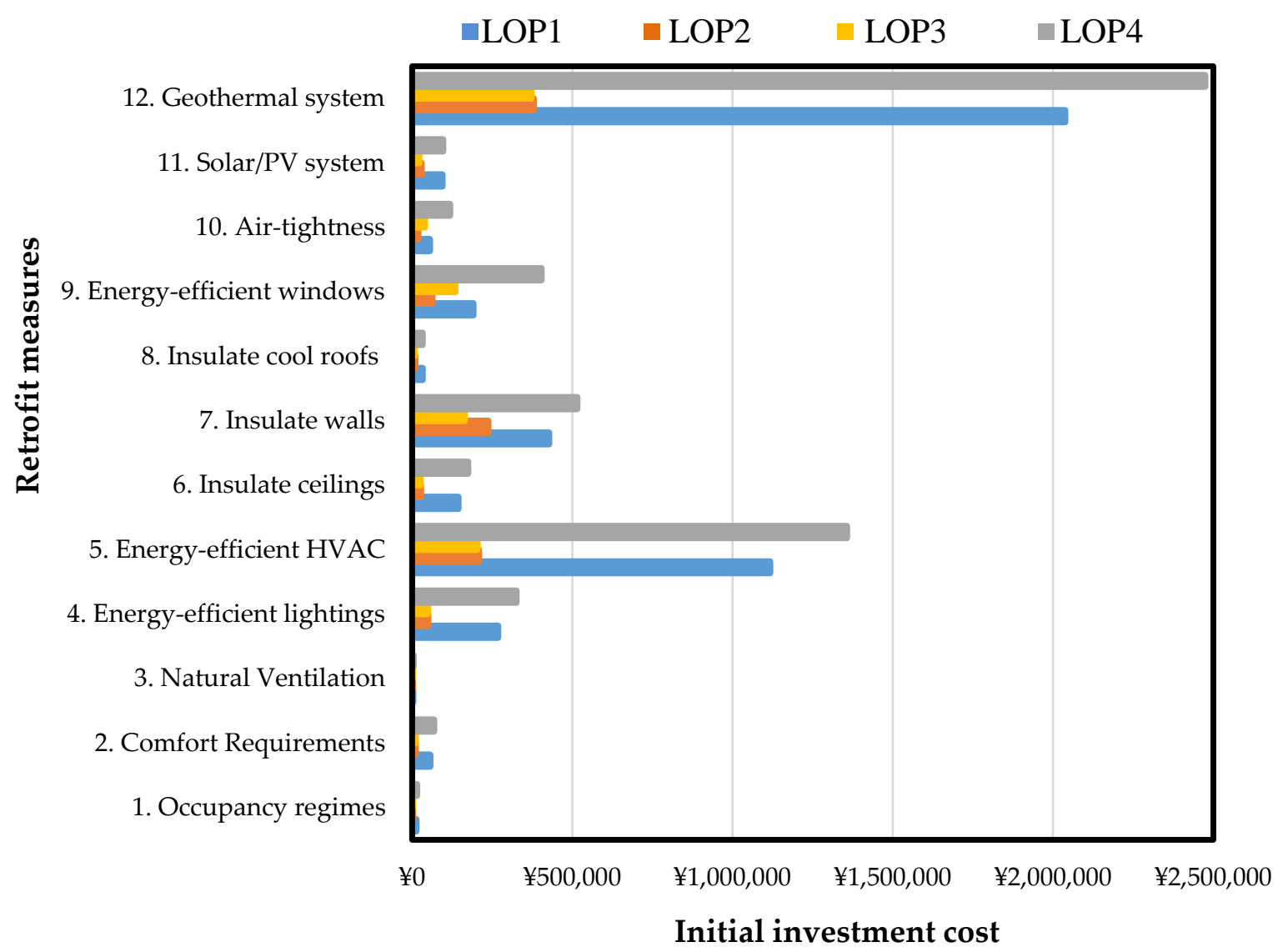

Fig. 3. Initial investment costs of retrofit measures on each prototype.

On the other hand, the annual saving (the energy cost saved within a year = energy reduced by measure $x$ electricity price $(870 \mathrm{RMB} / \mathrm{MWh})$ ) is analogous to the energy reduction impact. However, to evaluate the most impactful retrofit measure on an economic scale, a combination of the energy and economic implications is necessary. On this account, the PBP, which combines the annual savings (energy implication) and IC (economic implication) is crucial. The PBP identifies the most cost-beneficial measures as it refers to the time frame required for the annual savings to offset the IC. The most beneficial measure will be that with the lowest PBP, which is of utmost importance to investors as it relates to the quickest return on investment. Fig. 4 summarizes the PBP for each measure, as presented in Section S3. 


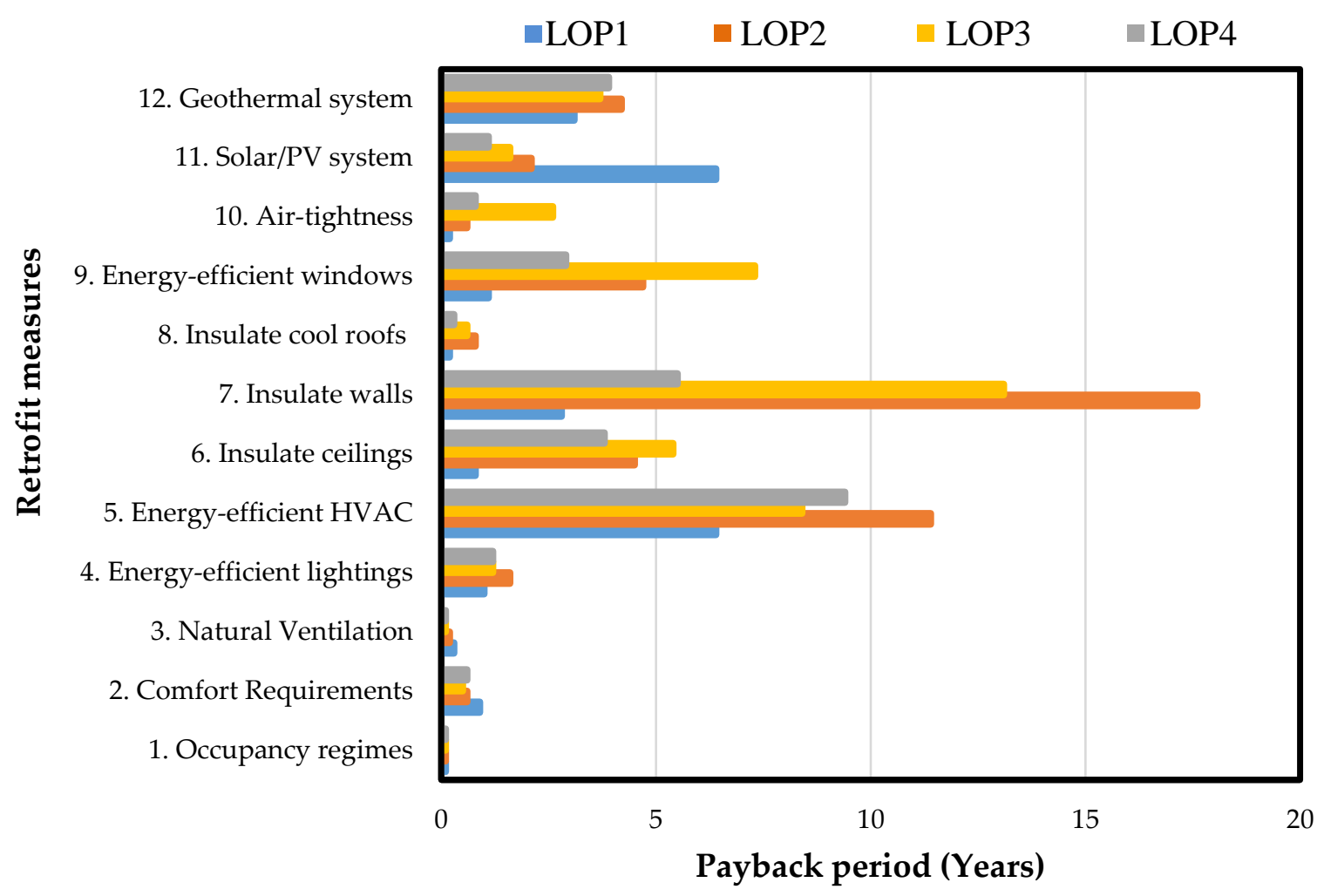

Fig. 4. Payback period of retrofit measures for each prototype.

Fig. 4 shows that changes in occupancy regime (average of 0.1 years) and natural ventilation (average of 0.2 years) demonstrated the shortest PBP, while HVAC system (average of 8.9 years) and upgrade in wall insulation (average of 9.8 years) displayed the longest PBP. The variation in PBP results from the varying offset of IC against the annual savings. About short PBP, some of the measures do not show a significant impact on building energy. For instance, natural ventilation and roof insulation displayed an average PBP of 0.2 years and 0.5 years but exhibited an average energy reduction of $2.41 \%$ and $8.05 \%$, respectively. This goes to elucidate the meagre energy impact of some measures that are cost-beneficial. To attain the objective of a low energy target for LOB in Shanghai, the most suitable retrofit solution should consider measures with high energy reduction impact and low PBP.

In the above context, Fig. 5 presents an overall representation of the economic and energy (or environmental) impact for each retrofit measure. In this form, there is clarity about measures that can suitably provide high energy reduction impact and low PBP for each LOP. Here, the size of the bubbles indicates the magnitude of the energy reduction impact, while the $y$-axis represents the corresponding PBP. Therefore, the most suitable retrofit strategy should include measures with large bubble size and positioned at the lowest level of the PBP-axis. From Fig. 5, these conditions are observed by measures 1, 4 and 8 (representing changes in occupancy regime, lighting and roof insulation, respectively) for all LOP. 
Besides, measure 2 (changes in comfort requirement) satisfies these conditions for the recent prototypes (LOP2, LOP3 and LOP4); while measure 6 (ceiling insulation upgrade) was only observed to satisfy these conditions in the aged LOP (LOP1). This variation is logical given that upgrade in the building envelope/façade should be more impactful on older buildings. Moreover, the impact of adjusting the comfort requirements is reinforced by the presence of an efficient building envelope/façade (as in the case of recent buildings). Furthermore, Fig. 5 depicts that measure 10 (airtightness upgrade) is beneficial for all prototypes except LOP3. This can be ascribed to the high W/W ratio of LOP3 and the associated high cost for the air-tightness of the windows. Similarly, measure 3 (natural ventilation) was more impactful for LOP3 and LOP4. Also, this effect is attributed to the high W/W ratio, which is beneficial for promoting natural ventilation in buildings.
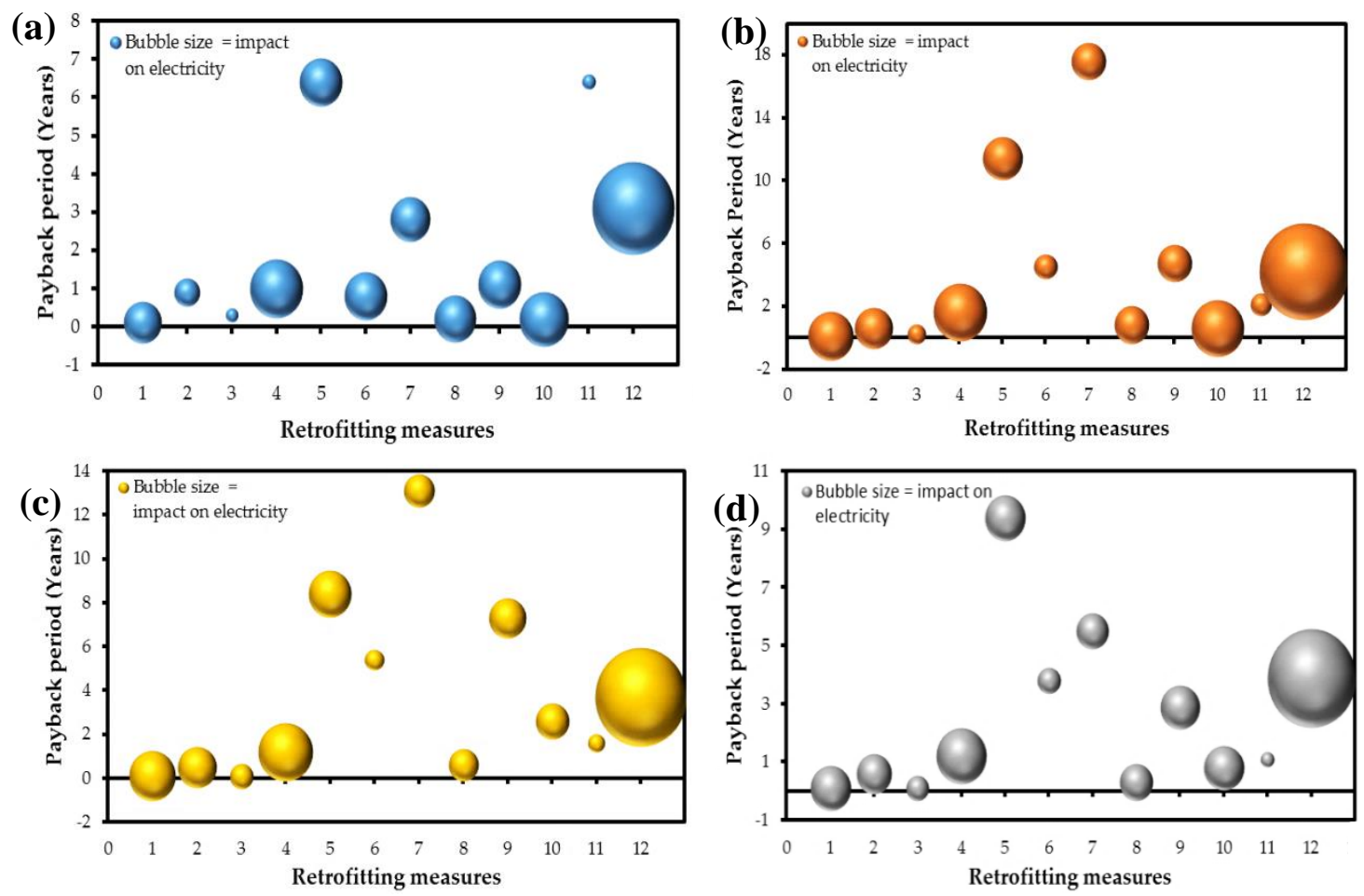

Fig. 5. Schematic comparism of the energy impact of each retrofit measure and their corresponding PBP for (a) LOP1, (b) LOP2, (c) LOP3, and (d) LOP4 prototypes. [Notation for the retrofit measures: 1 (occupancy regime), 2 (comfort requirements), 3 (natural ventilation), 4 (energy-efficient lightings), 5 (energy-efficient HVAC systems), 6 (ceilings insulation), 7 (wall insulation), 8 (roof insulation), 9 (energy-efficient windows), 10 (air-tightness), 11 (PV/solar system) and 12 (geothermal system installation).]

In summary, each retrofit measure demonstrates varying impact on the different LOP. Hence, a trade-off between the $3 \mathrm{E}$ implications is required in selecting the most suitable retrofit solution. Overall, the upgrade in occupancy regime, lighting efficiency and roof insulation are the most impactful measures, given their reasonably high energy 
reduction impact and low PBP. Other cost-effective and beneficial measures include comfort requirement adjustment and upgrade in ceiling insulation, air-tightness and natural ventilation. An integral strategy incorporating these measures will proffer a suitable retrofit solution for LOB in Shanghai. However, a critical 3E assessment of all possible combinatorial retrofit strategies is necessary.

\subsubsection{Building performance based on the combinatorial retrofit measures}

After assessing the impact of all individual measures, the possible combinations of the measures are assessed using the simplified mathematical equations (Section S1, supporting document). With the 12 selected specific retrofit measures, there are $2^{12}$ (4096) possible combinations for each building. However, given the relevance of the solar/PV system as a relatively low-cost RES with a substantial reducing potential of environmental impact, this system is incorporated into all possible combinations. Therefore, $2^{11}(2,048)$ possible combinations are considered in this study.

Fig. 6 shows the computed LCC (represented as total cost, TC), EC and IC profiles for LOP1 (Fig. 6 (a)), LOP2 (Fig. 6 (b)), LOP3 (Fig. 6 (c)) and LOP4 (Fig. 6 (d)). The raw data for the LCC, EC, IC and DL is presented in Section S4 (supporting document). The generated LCC profiles for LOP1, LOP2, LOP3 and LOP4 correspond with the trendline with an $\mathrm{R}^{2}$ value of $0.8351,0.7758,0.8726$, and 0.9053 , respectively. The EC and IC trendlines for each LOP also exhibited a reasonably high $\mathrm{R}^{2}$ value (>0.84). As observed in Fig. 6, the prototypes with no retrofit measure $(\mathrm{DL}=0 \%)$ has a zero IC and maximum EC. Contrarily, the strategy that combines all the retrofit measures $(\mathrm{DL}=$ $100 \%$ ) displayed the maximum IC and lowest EC. The minimum LCC is situated between these two boundaries.

\section{- Identifying the optimal retrofit solution}

One of the key objective function for the selection of an optimal retrofit solution involves the identification of the minimum LCC. From Fig. 6, the minimum LCC is attained at DL values of about $99.10 \%, 84.92 \%, 88.72 \%$ and $84.65 \%$ for LOP1, LOP2, LOP3 and LOP4, respectively. The corresponding TC (million RMB) are approximately 12.4, 2.4, 2.7 and 16.4 with IC (million RMB) of 4.2, 1.0, 0.9 and 4.5 for LOP1, LOP2, LOP3 and LOP4, respectively. These results confirm that the optimal retrofit solution for $\mathrm{C} 1$ buildings (LOP1) requires a higher degree of upgrade (denoted by the DL value) than the $\mathrm{C} 2$ buildings. Besides, LOP1 and LOP4 require higher IC to attain the optimal status due to their large building areas. LOP4 exhibited a higher IC than LOP1 due to the significant distinction in the retrofit prices for (1) the HVAC and geothermal systems (associated with larger building area), and (2) the window upgrade and air-tightness improvement (associated with larger W/W ratio). These findings highlight the impact of building features on building retrofitting projects and its associated IC [34, 36]. 
Also, approximately 89\%, 74\%, 78\% and 71\% reduction in EC was observed for LOP1, LOP2, LOP3 and LOP4, respectively at the minimum LCC from an initial EC value (million RMB) of 33.8, 5.4, 6.5 and 40.3 (using the EC profile, Fig. 6). The estimated reductions in EC also indicate a parallel reduction in EUI. Specifically, the EUI at minimum LCC for LOP1, LOP2, LOP3 and LOP4 is $13.69 \mathrm{kWh} / \mathrm{m}^{2}, 25.54 \mathrm{kWh} / \mathrm{m}^{2}$, $25.14 \mathrm{kWh} / \mathrm{m}^{2}$ and $35.25 \mathrm{kWh} / \mathrm{m}^{2}$, respectively. Overall, the EUI at optimal status is less than the regulated standard, $70-85 \mathrm{kWh} / \mathrm{m}^{2}$. 


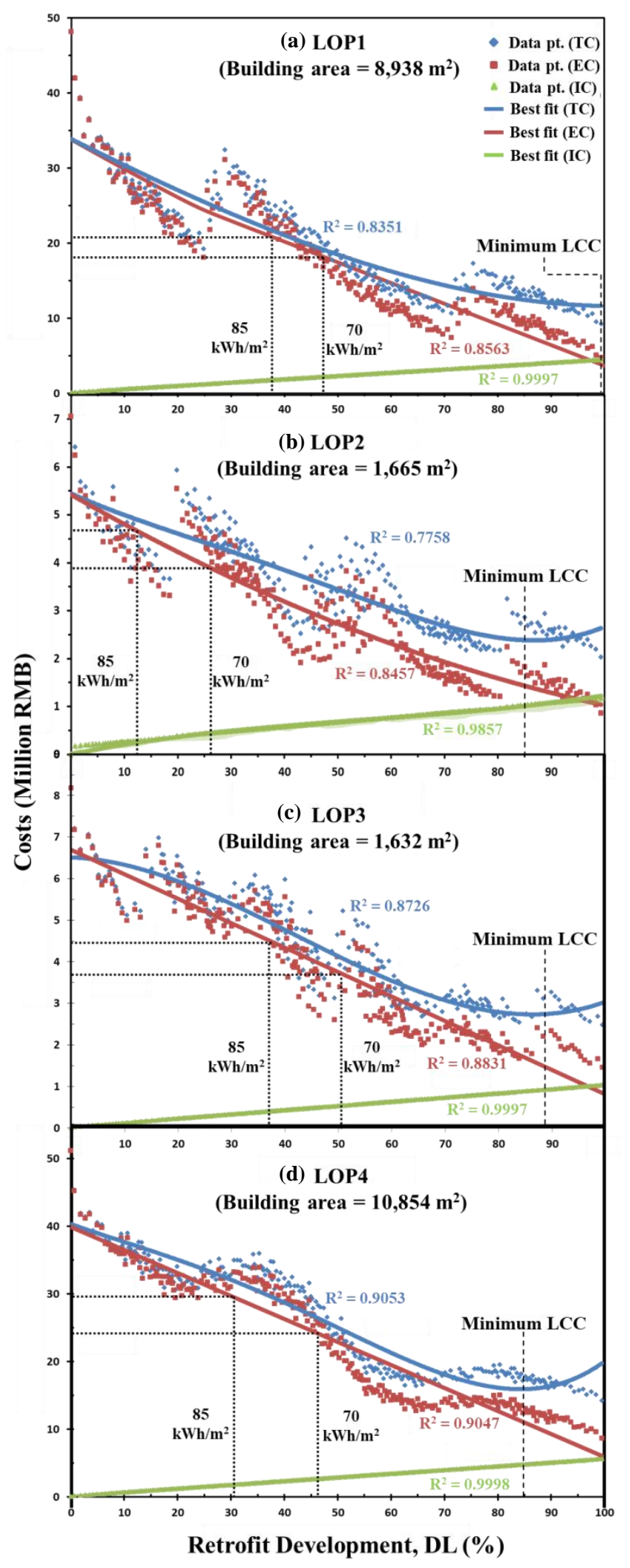

Fig. 6. Optimal retrofit strategy derived by the minimum LCC (TC) evaluation, and the retrofit development level required to achieve the set EUI targets for (a) LOP1, (b) LOP2, (c) LOP3, and (d) LOP4. $($ TC = total cost, EC = Energy cost, IC = Investment cost) 
- Identifying the suitable retrofit solution to achieve the set EUI targets

Concerning the regulated standards, Fig. 6 also indicates the minimal upgrade requirements to attain the 70 EUI and 85 EUI target in each prototype. The required upgrades were obtained by reading off the DL values that corresponds to the EC obtainable at the EUI targets. Specifically, the original EUI for LOP1, LOP2, LOP3 and LOP4 is approximated at $132.20 \mathrm{kWh} / \mathrm{m}^{2}, 98.52 \mathrm{kWh} / \mathrm{m}^{2}, 123.53 \mathrm{kWh} / \mathrm{m}^{2}$ and $116.71 \mathrm{kWh} / \mathrm{m}^{2}$, respectively. A reduction of these EUI values to the $70 \mathrm{kWh} / \mathrm{m}^{2}$ and $85 \mathrm{kWh} / \mathrm{m}^{2}$ targets will require a matching decrease in the EC values. At the $70 \mathrm{kWh} / \mathrm{m}^{2}$ target, the matching EC (million RMB) for LOP1, LOP2, LOP3 and LOP4 are estimated as $17.9,3.8,3.7$ and 24.2 , respectively; whereas for the $85 \mathrm{kWh} / \mathrm{m}^{2}$ target, the EC (million RMB) are 21.7, 4.7, 4.5 and 29.4, respectively.

Using these EC values, the DL required to attain the $70 \mathrm{kWh} / \mathrm{m}^{2}$ for LOP1, LOP2, LOP3 and LOP4 is approximately $47.2 \%, 26.5 \%, 50.2 \%$ and $46.9 \%$, respectively; whereas for the $85 \mathrm{kWh} / \mathrm{m}^{2}$ target, the DL is approximately $37.5 \%, 12.4 \%, 36.7 \%$ and $31.1 \%$, respectively. Expectedly, LOP2 required the least level of upgrade to attain the set EUI targets owing to its small building area and W/W ratio, which are part of the major factors to be highly considered in any retrofit project. With the DL values, the IC required to achieve the set EUI targets for each LOP is obtained. Subsequently, the probable combinatorial retrofit strategies with an IC above the required IC value are selected for further process.

About LOP1, Fig. 6 (a) shows that the DL values of $c a .47 .2 \%$ (for $70 \mathrm{kWh} / \mathrm{m}^{2}$ ) and $37.5 \%\left(85 \mathrm{kWh} / \mathrm{m}^{2}\right)$ require an IC value of $c a$. RMB 2.4 million and RMB 2.0 million, respectively. Above this required IC values, a total of 1332 retrofit strategies are identified. Using the AHC module of XLSTAT (version 2019.3.2) software, the strategies are partitioned into 3 clusters, with a centroid strategy that represents each cluster. The centroid strategy serves as the average primary strategy for the clustered class of strategies. A summary of the cluster analysis result is presented in Table 3. The combinatorial retrofit strategy comprising of adjusting comfort requirement, upgrade of lighting and HVAC systems, improved insulation of the building walls, roofs and windows, and PV installation is the major centroid strategy to achieve the $70 \mathrm{kWh} / \mathrm{m}^{2}$. This centroid strategy (denoted as strategy 25) represents 1319 (out of 1332) clustered strategies. On the other hand, an integrated adjustment of the comfort requirement, upgrade of lighting and HVAC systems, improved insulation of the building ceilings, walls and roofs, and PV installation is the major centroid strategy to achieve the 85 $\mathrm{kWh} / \mathrm{m}^{2}$. This centroid strategy is denoted as strategy 238, which represents 1079 (out of 1091) clustered strategies.

Concerning LOP2, Fig. 6 (b) shows that the DL values of $c a .26 .5 \%$ (for $70 \mathrm{kWh} / \mathrm{m}^{2}$ ) and $12.4 \%$ (for $85 \mathrm{kWh} / \mathrm{m}^{2}$ ) require an IC value of $c a$. RMB 0.4 million and RMB 0.3 million, respectively. When compared to that for LOP1 model, the lower IC value at 
the set EUI targets can be attributed to the smaller building area and its recent construction age. With these requirements, 1668 and 1865 combinatorial retrofit strategies were identified to achieve the 70 and 85 EUI targets, respectively. The cluster analysis (Table 3) reveals that the combinatorial retrofit solution comprising of adjustment of the comfort requirement, upgrade of lighting and HVAC systems, improved insulation of the building ceilings, walls and roofs, and PV installation is the major centroid strategy for attaining the set EUI targets. For the $70 \mathrm{kWh} / \mathrm{m}^{2}$, this strategy (denoted as strategy 774) represents 1654 (out of 1668) strategies, whereas the same strategy (denoted as strategy 971) represents 1853 (out of 1865) strategies for the $85 \mathrm{kWh} / \mathrm{m}^{2}$.

To attain the 70 EUI and 85 EUI targets for LOP3 (Fig. 6 (c)), DL values of $c a .50 .2 \%$ and $36.7 \%$ are required with an IC value of $c a$. RMB 0.5 million and RMB 0.4 million, respectively. The relative increase in IC when compared to LOP2 can be related to the difference in W/W ratio notwithstanding the smaller building area of LOP3. Using these values, 1021 and 1446 combinatorial retrofit strategies were identified to achieve the 70 and 85 EUI targets, respectively. The cluster analysis reveals that the centroid strategy for both EUI targets for LOP3 has the same combinatorial retrofit solution as that of LOP2. For the $70 \mathrm{kWh} / \mathrm{m}^{2}$, the major centroid strategy is denoted by strategy 140 which represents 1009 (out of 1021) strategies, whereas this strategy is denoted by strategy 345 which represents 1432 (out of 1446) strategies for the $85 \mathrm{kWh} / \mathrm{m}^{2}$ (Table $3)$.

Regarding LOP4 (Fig. 6 (d)), DL values of $c a .46 .9 \%$ and $31.1 \%$ with an IC value of $c a$. RMB 2.5 million and RMB 1.8 million are required to achieve the 70 and 85 EUI targets, respectively. Based on these results, 1096 and 1476 combinatorial retrofit strategies were identified, respectively. Remarkably, the major centroid strategy for both 70 and 85 EUI targets have the same combinatorial retrofit measures as that for LOP1. For the $70 \mathrm{kWh} / \mathrm{m}^{2}$, the centroid strategy is indicated as strategy 59, which represents 1084 (out of 1096) clustered strategies. On the other hand, the major centroid strategy (strategy 331) for the $85 \mathrm{kWh} / \mathrm{m}^{2}$ represents 1464 (out of 1476) clustered strategies (Table 3).

Table 4 summarises the results of this study. In summary, it is noted that an integral retrofit strategy consisting of adjustment in comfort requirement, upgrade of lighting, HVAC and building envelope (walls, roofs and ceilings), and PV installation is common for attaining the EUI targets across all prototypes (on a macro-scale). The only exception is that upgrade of windows rather than ceilings is included to attain the 70 EUI target for LOP with large building areas and relatively high W/W ratio (LOP1 and LOP4). This distinction in the results is logical given that a more beneficial trade-off between the energy and economic implication is likely in buildings with large building area and W/W ratio when the air-tightness and energy-efficiency of the windows are upgraded [35]. Similarly, the macro-scale analysis presents that the primary measures 
(as itemized in Table 4) necessary for attaining an optimal energy performance for all LOB stocks in Shanghai should include adjustments in occupancy regime, upgrade of HVAC and natural ventilation, improvement of cool roofs and installation of solar/PV and geothermal systems. Other necessary measures (but dependent on the building characteristics) include adjustments in comfort requirements, wall insulations, upgrade of windows and air-tightness.

Table 3. Cluster analysis of retrofit strategies to achieve the 70 and 85 EUI building targets. Full description of all combinatorial retrofit strategy and their respective dendrograms for each EUI target are presented in Sections S5 and S6 (supporting document), respectively.

\begin{tabular}{|c|c|c|c|c|c|}
\hline \multirow{2}{*}{$\begin{array}{l}\text { LOB } \\
\text { model }\end{array}$} & \multirow{2}{*}{$\begin{array}{l}\text { Cluster } \\
\text { Class }\end{array}$} & \multicolumn{2}{|c|}{85 EUI Target } & \multicolumn{2}{|c|}{70 EUI Target } \\
\hline & & $\begin{array}{r}\text { Centroid } \\
\text { strategy }\end{array}$ & $\begin{array}{r}\text { No. of } \\
\text { strategies }\end{array}$ & $\begin{array}{c}\text { Centroid } \\
\text { strategy }\end{array}$ & $\begin{array}{r}\text { No. of } \\
\text { strategies }\end{array}$ \\
\hline \multirow{4}{*}{ LOP1 } & 1 & 238 & 1319 & 25 & 1079 \\
\hline & 2 & 1304 & 12 & 1063 & 11 \\
\hline & 3 & 1332 & 1 & 1091 & 1 \\
\hline & Total & & 1332 & & 1091 \\
\hline \multirow{4}{*}{ LOP2 } & 1 & 971 & 1853 & 774 & 1654 \\
\hline & 2 & 1845 & 11 & 1648 & 13 \\
\hline & 3 & 1865 & 1 & 1668 & 1 \\
\hline & Total & & 1865 & & 1668 \\
\hline \multirow{4}{*}{ LOP3 } & 1 & 345 & 1432 & 140 & 1009 \\
\hline & 2 & 1430 & 13 & 1005 & 11 \\
\hline & 3 & 1446 & 1 & 1021 & 1 \\
\hline & Total & & 1446 & & 1021 \\
\hline \multirow{4}{*}{ LOP4 } & 1 & 331 & 1464 & 59 & 1084 \\
\hline & 2 & 1452 & 11 & 1072 & 11 \\
\hline & 3 & 1476 & 1 & 1096 & 1 \\
\hline & Total & & 1476 & & 1096 \\
\hline
\end{tabular}


Table 4. Summary of the selected combination of retrofit solutions for the proposed prototypes. (For macro-scale intervention at minimum LCC: the primary retrofit measures are those selected by all four prototypes, while the secondary measures are required by three of the prototypes.)

\begin{tabular}{|c|c|c|c|c|c|c|c|}
\hline \multirow[t]{2}{*}{ Measures } & \multirow{2}{*}{$\begin{array}{l}85 \text { EUI } \\
\text { target }^{+}\end{array}$} & \multicolumn{2}{|c|}{$\begin{array}{l}70 \text { EUI } \\
\text { target* }\end{array}$} & \multicolumn{4}{|c|}{ Minimum LCC } \\
\hline & & $\mathbf{A}$ & $\mathbf{B}$ & LOP1 & LOP2 & LOP3 & LOP3 \\
\hline $\begin{array}{l}\text { 1. Occupancy } \\
\text { regimes }\end{array}$ & & & & $\checkmark$ & $\checkmark$ & $\checkmark$ & $\checkmark$ \\
\hline $\begin{array}{l}\text { 2. Comfort } \\
\text { requirements }\end{array}$ & $\checkmark$ & $\checkmark$ & $\checkmark$ & & $\checkmark$ & $\checkmark$ & $\checkmark$ \\
\hline 3. Natural ventilation & & & & $\checkmark$ & $\checkmark$ & $\checkmark$ & $\checkmark$ \\
\hline $\begin{array}{l}\text { 4. Energy-efficient } \\
\text { lighting }\end{array}$ & $\checkmark$ & $\checkmark$ & $\checkmark$ & $\checkmark$ & & & \\
\hline $\begin{array}{l}\text { 5. Energy-efficient } \\
\text { HVAC }\end{array}$ & $\checkmark$ & $\checkmark$ & $\checkmark$ & $\checkmark$ & $\checkmark$ & $\checkmark$ & $\checkmark$ \\
\hline 6. Insulate ceilings & $\checkmark$ & $\checkmark$ & & $\checkmark$ & & & $\checkmark$ \\
\hline 7. Insulate walls & $\checkmark$ & $\checkmark$ & $\checkmark$ & $\checkmark$ & $\checkmark$ & $\checkmark$ & \\
\hline 8. Insulate cool roofs & $\checkmark$ & $\checkmark$ & $\checkmark$ & $\checkmark$ & $\checkmark$ & $\checkmark$ & $\checkmark$ \\
\hline $\begin{array}{l}\text { 9. Energy-efficient } \\
\text { Windows }\end{array}$ & & & $\checkmark$ & $\checkmark$ & & $\checkmark$ & $\checkmark$ \\
\hline 10. Air-tightness & & & & $\checkmark$ & $\checkmark$ & & $\checkmark$ \\
\hline $\begin{array}{l}\text { 11. Install solar PV } \\
\text { systems }\end{array}$ & & & & $\checkmark$ & $\checkmark$ & $\checkmark$ & $\checkmark$ \\
\hline $\begin{array}{l}\text { 12. Install } \\
\text { geothermal system }\end{array}$ & & & & $\checkmark$ & $\checkmark$ & $\checkmark$ & $\checkmark$ \\
\hline
\end{tabular}

${ }^{+}$Applies to all LOB prototypes

*A applies to LOP2 and LOP3 prototypes, while B applies to LOP1 and LOP4 prototypes

\subsection{Validation on a typical building}

First, an empirical approach was adopted to validate the simulation results. Here, the simulation results were compared with actual metered data for a typical building representing the LOP2 prototype (Bldg \#60 in Hong Xing Int'1 Square, No. 1969 Puxing Rd, Shanghai, see Fig. 7a). Comparatively, the simulated result is within a $\pm 5 \%$ error margin of the actual data. Following the empirical validation, it is also essential to verify the outcome of the retrofit solutions proposed by the combined simulation and numerical analysis. In details, the proposed retrofit solutions were simulated on the above mentioned typical building to confirm the outcomes after retrofitting. Table 5 
summarises the retrofit solutions and outcomes proposed to attain the required EUI target $\left(85 \mathrm{kWh} / \mathrm{m}^{2}\right)$ and the minimum LCC requirement. Excluding the RES, the other measures, as presented in Table 5, are inputted into the IES-VE building model (Fig. 7b) to validate the annual energy and $\mathrm{CO}_{2}$ emission savings.

Table 5. Proposed retrofit solution for the case study building LOP2.

Activity

1. Occupancy regimes (Moni strategies)

2. Comfort requirements

3. Natural ventilation

4. Energy-efficient Lightings

5. Energy-efficient HVAC

6. Insulate ceilings

7. Insulate walls

8. Insulate cool roofs

9. Energy-efficient windows

10. Air-tightness

11. Install solar PV systems*

12. Install geothermal system ${ }^{+}$

Energy reduction (\%)

Annual CO2 saved (Gg)

\section{LOP2}

*Solar/PV system capacity $=8.3 \mathrm{kWh} / \mathrm{m}^{2}(\sim 4.61 \mathrm{MWh})$

${ }^{+}$Geothermal system produced $50 \%$ ( 82.02 MWh) of the building energy demand
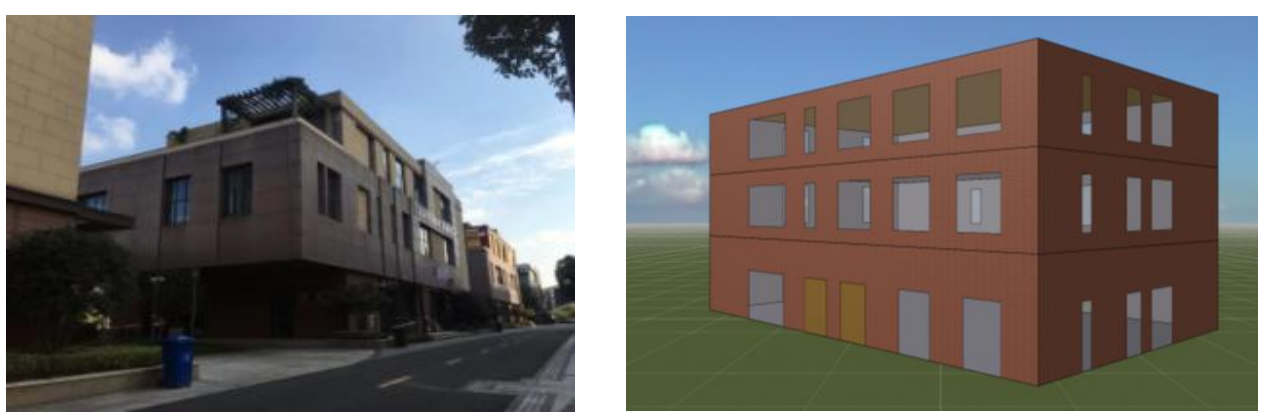

Fig. 7. (a) Original building and (b) IES-VE model representing LOP2 prototype for case study analysis. 


\subsubsection{EUI target}

Fig. 8 presents the simulated energy performance after implementing the proposed retrofit solution for the 85 EUI target. After retrofitting, the building energy reduced from the original 164.03 MWh (Section S2) to $141.64 \mathrm{MWh}$ (13.65\% reduction), which corresponds to a final EUI of $85.07 \mathrm{kWh} / \mathrm{m}^{2}$ with a matching $20 \%$ reduction in $\mathrm{CO}_{2}$ emission to $73,513 \mathrm{~kg} \mathrm{CO}_{2}$.

Comparatively, this depicts that the outcome of the proposed model is reliable with a $0.1 \%$ error margin. Hence, it is evident that integrating the adjustment of occupants' comfort level and upgrade of HVAC, lighting, ceilings, walls and roofs with a total initial investment of RMB 0.54 million is suitable to achieve the required EUI target for LOP2. However, given the electricity price of $870 \mathrm{RMB} / \mathrm{MWh}$, the estimated PBP will be longer than 20 years.

\begin{tabular}{|l|l|l|}
\hline & Electricity? (MWh) & \\
& & \\
\hline & & Electricity CE? (kgCO2) \\
\hline Date & hongxing.aps & hongxing.aps \\
\hline Jan 01-31 & & 9013 \\
\hline Feb 01-28 & 17.3669 & 6892 \\
\hline Mar 01-31 & 13.2802 & 4494 \\
\hline Apr 01-30 & 8.6587 & 2791 \\
\hline May 01-31 & 5.3784 & 4609 \\
\hline Jun 01-30 & 8.8805 & 6856 \\
\hline Jul 01-31 & 13.2097 & 9787 \\
\hline Aug 01-31 & 18.8582 & 9599 \\
\hline Sep 01-30 & 18.4956 & 6898 \\
\hline Oct 01-31 & 13.2900 & 3564 \\
\hline Nov 01-30 & 6.8671 & 3149 \\
\hline Dec 01-31 & 6.0667 & 5860 \\
\hline Summed total & 11.2916 & 73513 \\
\hline
\end{tabular}

Fig. 8. Validation result for EUI 85 target

\subsubsection{Minimum LCC}

At minimum LCC, the optimal retrofit strategy (with an estimated energy reduction of $74 \%$ ) was defined as a combination of nine individual retrofit measures: seven energyconserving measures and two energy-producing (RES) measures. However, given the challenge of simulating energy-producing measures with IES-VE, the RES was excluded in the simulation process and their impact was validated mathematically. Here, a two-step approach is employed to simplify the validation process.

Step 1: Simulation of the seven energy-conserving measures

Fig. 9 illustrates the simulated energy behaviour after retrofitting with the seven energyconserving measures. Without the RES, the simulated building energy (electricity) demand $\left(\mathrm{BEC}_{\mathrm{s}}\right)$ is $115.76 \mathrm{MWh}$ (29.42\% reduction). Similarly, $\mathrm{CO}_{2}$ emission reduced from $91,361 \mathrm{~kg}-\mathrm{CO}_{2}$ to $60,081 \mathrm{~kg}-\mathrm{CO}_{2}$. This environmental outcome (annual $\mathrm{CO}_{2}$ savings $=0.0313 \mathrm{Gg}_{-} \mathrm{CO}_{2}$ ) is much lesser than that proposed by the model framework 
$\left(0.1062 \mathrm{Gg}-\mathrm{CO}_{2}\right)$. This result verifies that the arithmetic sum of the $\mathrm{CO}_{2}$ savings from the individual retrofit measure does not accurately predict the actual $\mathrm{CO}_{2}$ emission behaviour. A probable reason for this distinction will be the synergistic effect resulting from the integration of the individual measures.

\begin{tabular}{|l|l|l|}
\hline & & \\
& & \\
\hline & & \\
\hline Date & hongxing.aps & hongxing.aps \\
\hline Jan 01-31 & & 5152 \\
\hline Feb 01-28 & 9.9267 & 3885 \\
\hline Mar 01-31 & 7.4858 & 3124 \\
\hline Apr 01-30 & 6.0196 & 2791 \\
\hline May 01-31 & 5.3784 & 4897 \\
\hline Jun 01-30 & 9.4359 & 6416 \\
\hline Jul 01-31 & 12.3631 & 8529 \\
\hline Aug 01-31 & 16.4339 & 8477 \\
\hline Sep 01-30 & 16.3331 & 6419 \\
\hline Oct 01-31 & 12.3681 & 4026 \\
\hline Nov 01-30 & 7.7572 & 2792 \\
\hline Dec 01-31 & 5.3800 & 3571 \\
\hline Summed total & 6.8808 & 60081 \\
\hline
\end{tabular}

Fig. 9. Validation result of minimum LCC

Step 2:

Considering the RES, the solar/PV and geothermal systems have fixed energy

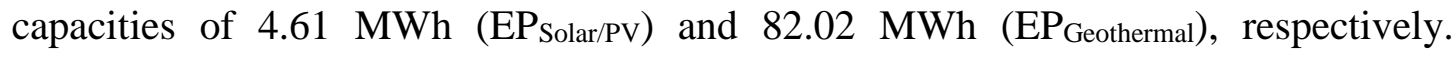
Assuming these are accurately simulated in the software, then the resultant building energy demand $\left(\mathrm{BEC}_{\mathrm{r}}\right)$ after retrofitting with the nine measures is:

$$
\begin{aligned}
B E C_{r} & =B E C_{s}-\left(E P_{\text {Geothermal }}+E P_{\text {Solar } / P V}\right) \\
& =115.76-(82.02+4.61) \mathrm{MWh} \\
& =29.13 \mathrm{MWh}
\end{aligned}
$$

Relative to the original model, there is an $82.24 \%$ energy reduction at minimum LCC, which bears a close match with that predicted by the model framework by $\sim 90 \%$. In summary, the retrofit solutions for attaining the set EUI target and minimum LCC are likely to reach their designated objectives. As such, the model framework is proven to be reliable. However, a more accurate assessment approach is required for predicting environmental implication.

\subsection{Decision based on the investor type}

Using the deciding criteria discussed in Section 2.2.5, Fig. 10 presents a comparison of the computed EUI:LCC percentage ratios of the respective DL, IC and ER at the stipulated EUI targets. The computed values are tabulated in Section S7 (supporting document). 
For the 85 EUI target, Fig. 10 shows that $\% \mathrm{IC}_{\text {EUI:LCC }}>\% \mathrm{ER}_{\mathrm{EUI}}$ LCC for all LOP. This result indicates that a relatively higher IC is required by the retrofit solution (for the EUI target) to achieve a commensurate energy reduction to that at minimum LCC. On this account, applying the retrofit solution for the minimum LCC is more suitable in scenario 1. In scenario 2, \%DLEUI:LCC $<\% \mathrm{ER}_{\mathrm{EUI}} \mathrm{LCC}$ for all prototypes except for LOP3. Here, a relatively lower degree of retrofit development is required to achieve a proportional energy reduction when compared to that at minimum LCC. Therefore, it is suggested that the retrofit solution for the EUI target is more suitable for LOP1, LOP2 and LOP4; whereas the optimal retrofit strategy is recommended for LOP3.

About scenario 1 for the 70 EUI target, the LCC retrofit solution is more appropriate for LOP1 and LOP3 (\% IC $\left.\mathrm{EUI}_{\mathrm{LCC}}>\% \mathrm{ER}_{\mathrm{EUI}: \mathrm{LCC}}\right)$. Contrarily, the 70 EUI retrofit solution is considered to be more suitable for LOP2. Lastly, the LOP4 model

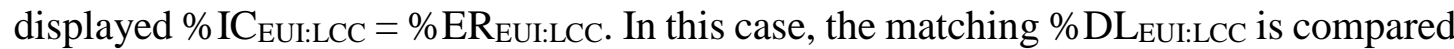
with \%EREUI:LCC as an additional condition. The results depict that \%DLEUI:LCC

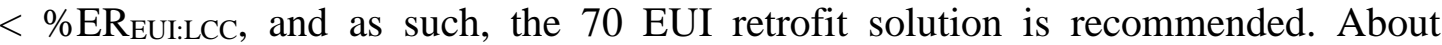
scenario 2, the EUI retrofit solution is more suited for all LOP (\%DLEUI:LCC $<\%$ EREUI:LCC) except for LOP3.

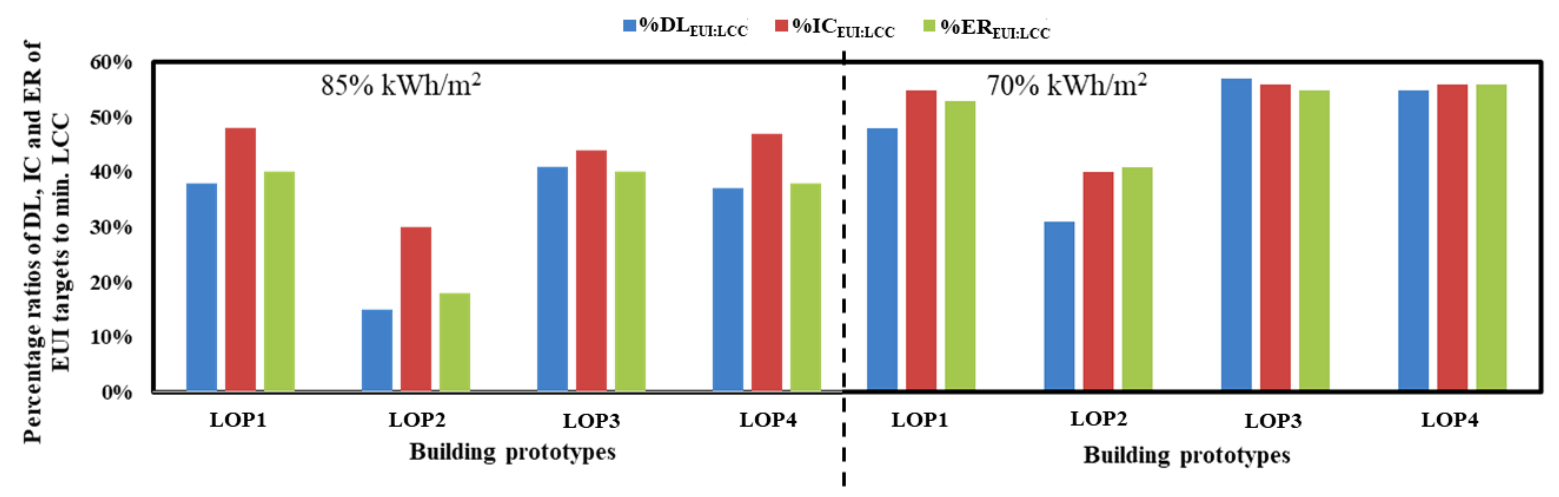

Fig. 10. Ratios of LCC outcomes (DL, IC and ER) achieved by each EUI targets.

\section{Conclusion}

Given the importance of upgrading buildings amidst urban development, this study provides an innovative multi-objective evaluating model for assessing retrofit alternatives on a macro-scale. The model proposes a comprehensive approach that integrates a data mining procedure into the multi-objective decision-making process to provide a simple and holistic assessment (energy, environmental and economic (3E) implications) of building retrofits. Also, the approach provides a methodological contribution that enables decision-makers to select the most reasonable retrofit solution by defining rational decision criteria based on the set performance targets. 
The model framework consists of three methodological models: building stock aggregation model, individualistic 3E model, and a life cycle cost (LCC)-environmental assessment model. The potential of the proposed model framework is demonstrated and validated using a case study analysis of achieving the set Chinese EUI targets for lowrise office buildings (LOB) in Shanghai. The results of the model define four prototypical buildings that describe the existing LOB blocks via the building stock aggregation model. Subsequently, a total of 12 commonly applied retrofit measures (both active and passive, varying from low to high-cost efforts) are individually assessed on each prototype. The results of this assessment provide input sensitivity data for a simplified LCC-environmental evaluation for 2,048 possible combinations of the retrofit measures. Finally, the most suitable retrofit solutions to achieve optimal building performance and the set EUI performance targets based on the $3 \mathrm{E}$ concerns are defined.

Independently, the different retrofit measures displayed varying $3 \mathrm{E}$ implications. However, a larger energy reduction impact was witnessed on buildings built before 2005 (C1) than on that built after 2005 (C2) when active measures are implemented. On the contrary, passive measures displayed a greater energy impact on $\mathrm{C} 2$ than on $\mathrm{C} 1$ buildings. Overall, the upgrade in lighting efficiency and air-tightness improvement are the most impactful measures across most of the buildings.

Jointly, a set of retrofit solutions are identified to satisfy the EUI target across all LOB prototypes. By employing a clustering approach, the numerous solutions are streamlined to the most likely macro-scale solution (combining the adjustment in comfort requirement, upgrade of lighting, HVAC and building envelope (walls, roofs and ceilings), and PV installation). Similarly, this study recommends that the primary retrofit measures to attain an optimal building performance for all LOB stocks in Shanghai should include adjustments in occupancy regime, upgrade of HVAC and natural ventilation, improvement of cool roofs, and installation of solar/PV and geothermal systems. Other necessary measures include adjustments in comfort requirements, upgrade of wall insulations, windows and air-tightness.

Considering the benefits of achieving the EUI targets and optimal performance, decision criteria based on the investors' priority was proposed to guide the selection on which retrofit solution to implement. Based on these criteria, the optimal retrofit solution is recommended for investors with investment cost as their primary priority. Contrarily, the EUI retrofit solution is the most suited for investors focused on environmental/energy concerns. Overall, the makeshift decision model offers investors a framework to select reasonable retrofit solutions based on different performance targets on a macro-scale. Depending on the distinctive features of the city or building typology, the obtained results for the case study could differ. However, the proposed approach remains valid for developing reliable retrofit solutions. 


\section{References}

1. Zheng, L. and J. Lai, Environmental and economic evaluations of building energy retrofits: Case study of a commercial building. Building and Environment, 2018. 145: p. 14-23.

2. Nägeli, C., et al., A service-life cycle approach to maintenance and energy retrofit planning for building portfolios. Building and Environment, 2019. 160: p. 106212.

3. Rysanek, A. and R. Choudhary, A decoupled whole-building simulation engine for rapid exhaustive search of low-carbon and low-energy building refurbishment options. Building and Environment, 2012. 50: p. 21-33.

4. Chidiac, S., et al., A screening methodology for implementing cost effective energy retrofit measures in Canadian office buildings. Energy and Buildings, 2011. 43(2-3): p. 614-620.

5. Shao, Y., P. Geyer, and W. Lang, Integrating requirement analysis and multiobjective optimization for office building energy retrofit strategies. Energy and Buildings, 2014. 82: p. 356-368.

6. Wang, B. and X. Xia, Optimal maintenance planning for building energy efficiency retrofitting from optimization and control system perspectives. Energy and Buildings, 2015. 96: p. 299-308.

7. Roberti, F., et al., Energy retrofit and conservation of a historic building using multi-objective optimization and an analytic hierarchy process. Energy and Buildings, 2017. 138: p. 1-10.

8. Jafari, A. and V. Valentin, Selection of optimization objectives for decisionmaking in building energy retrofits. Building and Environment, 2018. 130: p. 94-103.

9. Zheng, D., L. Yu, and L. Wang, A techno-economic-risk decision-making methodology for large-scale building energy efficiency retrofit using Monte Carlo simulation. Energy, 2019. 189: p. 116169.

10. Zheng, D., et al., A screening methodology for building multiple energy retrofit measures package considering economic and risk aspects. Journal of Cleaner Production, 2019. 208: p. 1587-1602.

11. Chen, X., et al., Multi-Criteria Assessment Approach for a Residential Building Retrofit in Norway. Energy and Buildings, 2019: p. 109668.

12. Jafari, A. and V. Valentin, An optimization framework for building energy retrofits decision-making. Building and Environment, 2017. 115: p. 118-129.

13. Mauro, G.M., et al., A new methodology for investigating the cost-optimality of energy retrofitting a building category. Energy and Buildings, 2015. 107: p. 456-478. 
14. Wang, B., X. Xia, and J. Zhang, A multi-objective optimization model for the life-cycle cost analysis and retrofitting planning of buildings. Energy and Buildings, 2014. 77: p. 227-235.

15. Allacker, K., et al., Energy simulation and LCA for macro-scale analysis of eco-innovations in the housing stock. The International Journal of Life Cycle Assessment, 2019. 24(6): p. 989-1008.

16. Lotteau, M., et al., Critical review of life cycle assessment (LCA) for the built environment at the neighborhood scale. Building and Environment, 2015. 93: p. 165-178.

17. Mastrucci, A., et al., Life Cycle Assessment of building stocks from urban to transnational scales: A review. Renewable and Sustainable Energy Reviews, 2017. 74: p. 316-332.

18. Shen, P., et al., Rapid multi-objective optimization with multi-year future weather condition and decision-making support for building retrofit. Energy, 2019. 172: p. 892-912.

19. Hong, Y., et al., Correlation between building characteristics and associated energy consumption: Prototyping low-rise office buildings in Shanghai.

Energy and Buildings, 2020. 217: p. 109959.

20. Crawley, D.B., et al., Contrasting the capabilities of building energy performance simulation programs. Building and Environment, 2008. 43(4): p. 661-673.

21. Jafari, A. and V. Valentin, Decision-making life-cycle cost analysis model for energy-efficient housing retrofits. International Journal of Sustainable Building Technology and Urban Development, 2015. 6(3): p. 173-187.

22. Pistore, L., et al., A stepwise approach integrating feature selection, regression techniques and cluster analysis to identify primary retrofit interventions on large stocks of buildings. Sustainable Cities and Society, 2019. 47: p. 101438.

23. Hong, Y., W. Deng, and C.I. Ezeh, Low-rise Office Retrofit: Prerequisite for Sustainable and Green Buildings in Shanghai. IOP Conference Series: Earth and Environmental Science, 2019. 281: p. 012025.

24. Hong, Y., et al., Building Energy Retrofit Measures in Hot-Summer-ColdWinter Climates: A Case Study in Shanghai. Energies, 2019. 12(17): p. 3393.

25. MOHURD, Standard for energy consumption of building GB/T 51161-2016. 2016.

26. MOHURD, Design standard for energy efficiency of public buildings GB50189-2015, Ministry of Housing and Urban-Rural Development of the China, Editor. 2015: China.

27. CIBSE, Energy Efficiency in Buildings: CIBSE Guide F Chartered Institution of Building Services Engineers. 2004, London: Chartered Institution of Building Services Engineers. 
28. Ma, Z., et al., Existing building retrofits: Methodology and state-of-the-art. Energy and Buildings, 2012. 55: p. 889-902.

29. Li, Y., et al., The Existing Building Sustainable Retrofit in China-A Review and Case Study. Procedia Engineering, 2017. 205: p. 3638-3645.

30. Hong, Y., et al., Attaining sustainability in built environment: Review of green retrofit measures for existing buildings. IOP Conference Series: Earth and Environmental Science, 2019. 227: p. 042051.

31. MOHURD, Public Building Energy Saving Design Standard, GB-50189. China National Code, 2005.

32. Papadopoulos, S., et al., Rethinking HVAC temperature setpoints in commercial buildings: The potential for zero-cost energy savings and comfort improvement in different climates. Building and Environment, 2019. 155: p. 350-359.

33. Shao, F., Case Study: Measurement and Analysis of Incremental Cost of Green Buildings. 2019:

http://www.360doc2.net/wxarticlenew/805953636.html.

34. Yeom, S., et al., Determining the optimal window size of office buildings considering the workers' task performance and the building's energy consumption. Building and Environment, 2020: p. 106872.

35. Troup, L., et al., Effect of window-to-wall ratio on measured energy consumption in US office buildings. Energy and Buildings, 2019. 203: p. 109434.

36. Kim, D., et al., Net-zero energy building design and life-cycle cost analysis with air-source variable refrigerant flow and distributed photovoltaic systems. Renewable and Sustainable Energy Reviews, 2020. 118: p. 109508. 